University of New Hampshire

University of New Hampshire Scholars' Repository

Master's Theses and Capstones

Student Scholarship

Winter 2011

\title{
Identification and characterization of Photorhabdus temperata mutants altered in hemolysis and virulence
}

Christine A. Chapman

University of New Hampshire, Durham

Follow this and additional works at: https://scholars.unh.edu/thesis

\section{Recommended Citation}

Chapman, Christine A., "Identification and characterization of Photorhabdus temperata mutants altered in hemolysis and virulence" (2011). Master's Theses and Capstones. 679.

https://scholars.unh.edu/thesis/679

This Thesis is brought to you for free and open access by the Student Scholarship at University of New Hampshire Scholars' Repository. It has been accepted for inclusion in Master's Theses and Capstones by an authorized administrator of University of New Hampshire Scholars' Repository. For more information, please contact Scholarly.Communication@unh.edu. 


\title{
IDENTIFICATION AND CHARACTERIZATION OF PHOTORHABDUS TEMPERATA MUTANTS ALTERED IN HEMOLYSIS AND VIRULENCE
}

BY

CHRISTINE A. CHAPMAN

B.S., University of Mary Washington, 2008

\section{THESIS}

Submitted to the University of New Hampshire in Partial Fulfillment of the Requirements for the Degree of

\author{
Master of Science \\ in \\ Microbiology
}

December, 2011 
UM! Number: 1507817

All rights reserved

INFORMATION TO ALL USERS

The quality of this reproduction is dependent upon the quality of the copy submitted.

In the unlikely event that the author did not send a complete manuscript and there are missing pages, these will be noted. Also, if material had to be removed, a note will indicate the deletion.

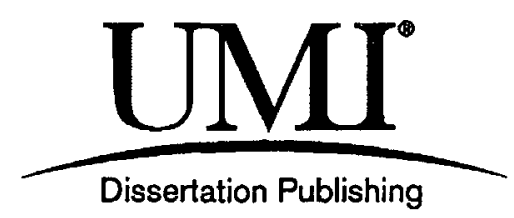

UMI 1507817

Copyright 2012 by ProQuest LLC.

All rights reserved. This edition of the work is protected against unauthorized copying under Title 17, United States Code.

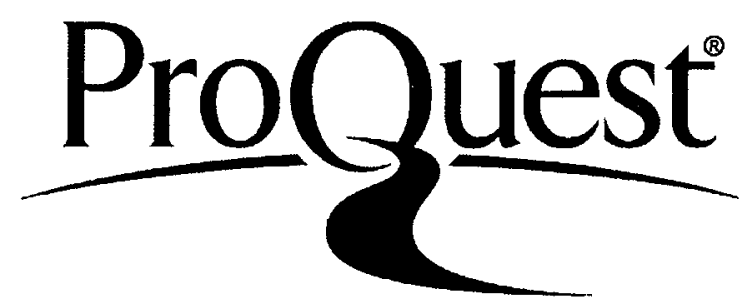

ProQuest LLC

789 East Eisenhower Parkway

P.O. Box 1346

Ann Arbor, MI 48106-1346 
This thesis has been examined and approved.

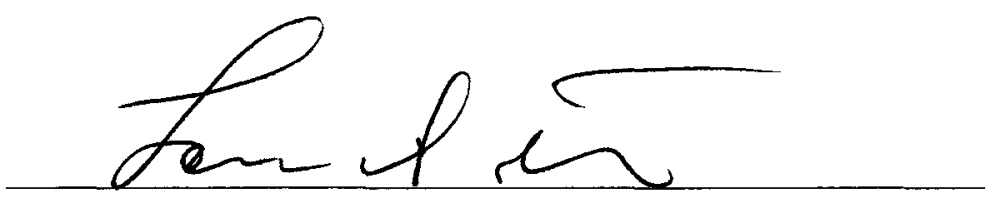

Thesis Director, Louis S. Pisa,

Professor of Microbiology and Genetics

PAtella Hatch

Estelle Hrabak, Associate Professor of

Genetics and Molecular Biology

Frank Rode

Frank Rodgers, Professor of Microbiology

December 2, 2011

Date 


\section{DEDICATION}

This thesis is dedicated to my fiancé, Colin Deyman.

Without you, I would have drowned. 


\section{ACKNOWLEDGEMENTS}

Funding for this project was provided in part by USDA NIFA 2009-35302-05257, the Graduate School Summer TA Fellowship, and UNH COLSA. Travel funding was provided by the UNH Graduate School and MCBS Department. I would like to sincerely thank my committee members for their support, guidance, and unending knowledge: Dr. Estelle Hrabak, for her expertise in molecular troubleshooting, Dr. Frank Rodgers, for providing me with valuable teaching experience, and last but not least my advisor, Dr. Louis Tisa, for both challenging and encouraging me throughout my project.

Thank you to all past and present members of the Tisa lab: Brandye Michaels for constructing the mutant library, Nick Beauchemin for his knowledge of laboratory techniques, Teal Furnholm for teaching me some of the most useful things I learned in grad school, Lauren Petersen for help with my quantitative hemolysis assays, Umija Duraković and Sheldon Hurst for help with molecular work, and especially Cíntia Félix for helping me with an endless list of troubleshooting, experimentation, data interpretation, and teaching, as well as countless hours of amusement. Thank you also to Jack Lepine for all his help with my Southern blot.

Thank you to all my friends who made graduate school an experience to remember: Keith Ferguson, Jess Jarett, Cara Fiore, Jenny Mahoney, Jessie Wishart, Hannah Bullock, Jong Yu, Muhammad Arif, and Seana Fraser.

A big thank you goes to my fiancé Colin Deyman for always being by my side through the bizarre, untamed, and deranged moments of grad school. Also, to my parents Carol and Scott, my sister Corinne, and the rest of my family: thank you for being a constant source of support, love, confidence, and entertainment. 


\section{TABLE OF CONTENTS}

I. INTRODUCTION

ENTOMOPATHOGENIC NEMATODES AND AGRICULTURE

PHOTORHABDUS TEMPERATA AND RELATED SPECIES

PHOTORHABDUS AND HETERORHABDITIS: PARTNERS IN CRIME

VIRULENCE MECHANISMS

HEMOLYSIN ACTIVITY AND FUNCTION

RESEARCH AIMS AND SIGNIFICANCE

II. MATERIALS AND METHODS

16

BACTERIAL STRAINS AND GROWTH CONDITIONS

16

HEMOLYSIS ASSAY TO IDENTIFy MUTANTS ALTERED IN HEMOLYTIC ABILITY 20

IN VITRO INSECT PATHOGENESIS ASSAY

PHYSIOLOGICAL ASSAYS

QUANTITATIVE HEMOLYSIS ASSAY

MOLECULAR CHARACTERIZATION

RESTRICTION FRAGMENT LENGTH POLYMORPHISM

CONFIRMATION OF TRANSPOSON INSERTION SITES

$\begin{array}{ll}\text { RNA EXTRACTION } & 31\end{array}$

REVERSE TRANSCRIPTION POLYMERASE CHAIN REACTION (RT-PCR)

$\begin{array}{ll}\text { SOUTHERN HYBRIDIZATION } & 32\end{array}$

\begin{tabular}{llr} 
III. & RESULTS & 35 \\
\hline IDENTIFICATION OF HEMOLYSIS MUTANTS & 35 \\
PHYSIOLOGICAL CHARACTERIZATION OF THE HEMOLYSIS MUTANTS & 38
\end{tabular}


IDENTIFICATION OF PATHOGENESIS MUTANTS

CONFIRMATION OF PATHOGENESIS MUTANTS 48

FURTHER PHENOTYPIC CHARACTERIZATION OF

CONFIRMED PATHOGENESIS MUTANTS 50

QUANTIFICATION OF PATHOgENESIS MUtANT HEMOLYTIC ACTIVITY

MOLECULAR CHARACTERIZATION OF VIRULENCE MUTANTS

CONFIRMATION OF TRANSPOSON INSERTION SITES BY PCR 61

IV. DISCUSSION 64

IDENTIFICATION OF MUTANTS ALTERED IN HEMOLYSIS AND PATHOGENESIS 64

MULTIPLE HEMOLYSINS ARE ACTIVE IN PHOTORHABDUS

HEMOLYTIC ACTIVITY IN PHOTORHABDUS IS CELL-ASSOCIATED

HEMOLYSIS MAY NOT BE REQUIRED FOR FULL VIRULENCE

REGULATION OF HEMOLYSIS AND VIRULENCE IN PHOTORHABDUS

MEMBRANE FUSION PROTEIN PRTC IS INVOLVED IN HEMOLYSIS

DisCREPANCIES IN PLEIOTROPIC EFFECTS OF

IDENTICAL MUTANTS 50 C5 AND 51 F9 72

REGULATORY EFFECTS OF THE

CARBAMOYL-PHOSPHATE SYNTHASE LARGE CHAIN 73

10A C11 AND 10A H12 ARE IDENTICAL EXORIBONUCLEASE II MUTANTS $\quad 75$

79 B5 IS AN RNA PYROPHOSPHOHYDROLASE (RPPH) MUTANT

MULTIPLE RNASES MAY Be INVOLVED IN THE REGULATION OF PATHOGENESIS 77

$\begin{array}{ll}\text { SIGNIFICANCE } & 78\end{array}$

$\begin{array}{ll}\text { FUTURE DIRECTIONS } & 79\end{array}$

LIST OF REFERENCES $\quad 80$ 


\section{LIST OF TABLES}

TABLE 1. BACTERIAL STRAINS AND PLASMIDS USED IN THIS STUDY 17

TABLE 2. PRIMERS USED IN THIS STUDY 30

TABLE 3. HEMOLYSIS SCREENING RESULTS: MUTANT HEMOLYTIC CATEGORIES 37

TABLE 4. PHYSIOLOGICAL PROPERTIES OF P. TEMPERATA MUTANTS ALTERED IN HEMOLYTIC ACTIVITY AND THEIR PARENTAL WILD TYPES 41

TABLE 5. HEMOLYSIS MUTANTS ALTERED IN INSECT PATHOGENESIS AS IDENTIFIED BY PRELIMINARY SCREENING

TABLE 6. QUANTITATIVE PHYSIOLOGICAL ANALYSIS OF 10 MUTANTS ALTERED IN HEMOLYTIC ACTIVITY AND DELAYED IN VIRULENCE

TABLE 7. HEMOLYTIC UNITS OF PARENTAL WILD TYPES AND PATHOGENESIS MUTANTS OVER TIME IN A LIQUID HEMOLYSIS ASSAY USING DILUTED CULTURE 


\section{LIST OF FIGURES}

FIGURE 1. THE LIFE CYCLE OF THE PHOTORHABDUS-HETERORHABDITIS ASSOCIATION

FIGURE 2. EXPERIMENTAL DESIGN FOR THE STUDY OF HEMOLYSIS AND VIRULENCE IN P. TEMPERATA

FIGURE 3. HEMOLYSIS PLATE ASSAY FOR THE SCREENING AND IDENTIFICATION OF HEMOLYTIC MUTANTS

21

FIGURE 4. IN VITRO INSECT PATHOGENESIS ASSAY

FIGURE 5. SELECTED HEMOLYSIS MUTANTS WERE ASSESSED FOR GROWTH DEFECTS VIA A 24-H GROWTH ASSAY

FIGURE 6. THE IN VITRO INSECT PATHOGENESIS ASSAY IDENTIFIED 25 HEMOLYTIC MUTANTS THAT EXHIBITED A DELAYED RESPONSE IN PATHOGENESIS

FIGURE 7. THE EFFECT OF CELL DOSAGE [MULTIPLICITY OF INFECTION (MOI)] ON INSECT PATHOGENESIS BY THE HEMOLYTIC MUTANTS

FIGURE 8. HEMOLYTIC UNITS VS. TIME IN A LIQUID HEMOLYSIS ASSAY

FIGURE 9. SOUTHERN BLOTTING CONFIRMED SINGLE TRANSPOSON INSERTIONS FOR THE PATHOGENESIS MUTANTS

FIGURE 10. CONFIRMATION OF TRANSPOSON INSERTION SITES VIA PCR 


\begin{abstract}
IDENTIFICATION AND CHARACTERIZATION OF PHOTORHABDUS TEMPERATA MUTANTS ALTERED IN HEMOLYSIS AND VIRULENCE
\end{abstract}

by

\author{
Christine A. Chapman
}

University of New Hampshire, December, 2011

Photorhabdus temperata is an invertebrate pathogen and nematode symbiont that is commonly used as a biological control agent in the management of commercial crop pests. The focus of this study was to investigate the poorly understood molecular elements involved in the expression of hemolysis and virulence in this bacterium. A 10,000 transposant library was screened using a blood agar plate assay to identify mutants altered in hemolytic activity. A total of 74 mutants displaying defective, delayed, or early hemolysis were identified and subsequently tested for altered virulence in the Greater Waxmoth, Galleria mellonella, using an in vitro mortality assay. Ten mutants delayed in pathogenesis were identified. Molecular analysis identified the sites of transposon insertion in 16 hemolysis mutants, eight of which also displayed delayed virulence. A critical finding of this study was the involvement of RNases in the regulation of hemolysis and pathogenesis. 


\section{CHAPTER I}

\section{INTRODUCTION}

\section{ENTOMOPATHOGENIC NEMATODES AND AGRICULTURE}

In the United States alone, the agricultural industry spends $\$ 10$ billion on pesticide use annually (Pimentel and Greiner, 1997) with a significant portion of this cost designated to the control of commercial crop insects. Still, $13 \%$ of all potential crops in the U.S. are destroyed due to insect damage (Pimentel, 1997). The necessity to control economically detrimental pests has resulted in the widespread use of potent chemical insecticides. Although historically effective, recent data highlight marked disadvantages as well as the decreasing efficacy of such chemicals. Concerns with chemical pesticide use include harm to nontarget organisms via contamination of soil and groundwater, biomagnification, and elimination of beneficial competitor insects (Chattopadhyay et al., 2004). Veterinary use of broad spectrum pesticides risks contaminating products in the meat and dairy industries as well (Georgis et al., 2006). These chemicals tend to degrade slowly or not at all, resulting in environmental persistence and toxicity to humans (Chattopadhyay et al., 2004). Furthermore, the recent emergence of pesticide-resistant insects has necessitated the use of higher dosages and newly-developed chemicals. 
Entomopathogenic nematodes have been in use as biological control agents in the United States since the 1980's (Georgis et al., 2006) and are growing in popularity in response to the call for reduced chemical pesticide use. Entomopathogenic nematodes are naturally soil-dwelling roundworms that infect larval-stage insects. The two genera of nematode used as biocontrol agents are Heterorhabditis and Steinernema, which form symbiotic relationships with the bacteria Photorhabdus and Xenorhabdus, respectively (Boemare et al., 1996). The exploitation of this natural symbiosis for pest control in agriculture offers numerous benefits over conventional chemical insecticide use. Entomopathogenic nematodes have a broad host range, capable of infecting over 200 species of insects (Georgis et al., 2006), many of which are commercial crop pests. Additionally, the symbiotic bacterial species are a much safer alternative for animals and humans alike as they do not target vertebrate species (Boemare et al., 1996). The risk for persistence and contamination is eliminated because nematodes do not accumulate in the environment. Because these species are actively predacious, they offer a high efficacy for insect control. The nematodes can be dispersed via traditional mechanisms used for pesticides, such as ground and aerial sprayers and irrigation systems (Chattopadhyay et al., 2004; Georgis, 1990), making the application of this type of biocontrol agent just as feasible as chemical insecticides. Finally, the use of organic biological control agent eliminates the risk of insects developing pesticide resistance.

\section{PHOTORHABDUS TEMPERATA AND RELATED SPECIES}

The genus Photorhabdus is comprised of three closely related but unique species, Photorhabdus temperata, Photorhabdus luminescens, and Photorhabdus asymbiotica, 
which are further divided into subspecies based on phenotypic characteristics and 16S rDNA diversity (Fischer-Le Saux et al., 1999; Waterfield et al., 2009). All members of the Photorhabdus genus, however, are defined by several core characteristics. The Photorhabdus bacterium is a gram-negative, rod-shaped, facultatively-anaerobic, motile member of the Enterobacteriaceae and is the only known terrestrial bioluminescent bacterium (Gerrard et al., 2011; Waterfield et al., 2009). Photorhabdus lives in a mutualistic symbiotic relationship with heterorhabditid nematodes and is also pathogenic to insects (Waterfield et al., 2009).

A peculiar aspect of the Photorhabdus life cycle is the transition from the typical wild-type form to a secondary form that exhibits a number of phenotypic changes. This rare phenotypic switch is referred to as phase variation and is believed to occur under conditions of prolonged laboratory cultivation (Akhurst, 1980). These two forms differ in their ability to absorb dyes on differential culture media including MacConkey, NBTA, and EMB agar. Additionally, the secondary variant has decreased or defective activity of extracellular enzymes, antimicrobial activity, and bioluminescence (Lanois et al., 2011).

Photorhabdus is closely related to a sister species, Xenorhabdus. In 1993, Boemare et al. proposed the transfer of Photorhabdus to its own genus based on DNA relatedness. In 2003, Duchaud et al. released the complete genome sequence of $P$. luminescens strain TT01. P. asymbiotica strain ATCC43949 has also been released (Wilkinson et al., 2009). $P$. asymbiotica is the clinical strain, which has been implicated in a few cases of human infection. The presence of a plasmid allows this species to grow at $37^{\circ} \mathrm{C}$, while the others cannot (Wilkinson et al., 2009). Currently, the P. temperata NC19 genome is being completed (Tisa, unpublished). 


\section{Photorhabdus and Heterorhabditis: Partners in CRIME}

$P$. temperata has a multiphasic life cycle requiring both pathogenesis of insects and a beneficial symbiosis with the nematode Heterorhabditis bacteriophora (Figure 1). Together, these mutualist entomopathogens infect a wide variety of insects where Photorhabdus assumes the role of a highly virulent pathogen. The pathogenic nature of Photorhabdus further supports the growth and development of Heterorhabditis within the insect host, thereby linking the two in a continuous cycle of symbiosis and pathogenesis.

Heterorhabditis bacteriophora is a soil-dwelling entomopathogenic nematode which carries Photorhabdus within its intestine (Burnell and Stock, 2000). During its infective juvenile (IJ) stage, $H$. bacteriophora is free-living in the environment and is actively predacious against a variety of larval insects. The IJs infect suitable larval hosts via natural openings including the mouth, anus, and spiracles, or by penetrating the insect's cuticle directly. Once inside the insect's hemocoel, the nematodes regurgitate the bacterial cells which immediately begin working to break down the host's tissues (Ciche and Ensign, 2003). Although the nematodes themselves may inflict structural damage on the insect contributing to mortality, the action of potent exotoxins secreted by Photorhabdus ultimately destroys the insect (Burnell and Stock, 2000).

Photorhabdus secretes a variety of toxins that kill the host in roughly 48 hours (Brillard et al., 2002; Burnell and Stock, 2000). Photorhabdus also releases exoenzymes, such as proteases, lipases, lipopolysaccharides, and cytolysins, within the hemocoel. The enzymes produced by the bacterial cells continue to degrade the internal environment of the insect, creating a milieu of nutrients in which the IJs mature into adult hermaphrodites and begin several generations of reproduction within the cadaver (Goodrich-Blair and 
Clarke, 2007). This reproductive cycle lasts for two to three weeks before a new generation of IJs release a signal which triggers the uptake of Photorhabdus cells into the nematode intestine. The symbiotic pair then exits the cadaver and disperses into the environment where the IJs begin searching for new prey. 


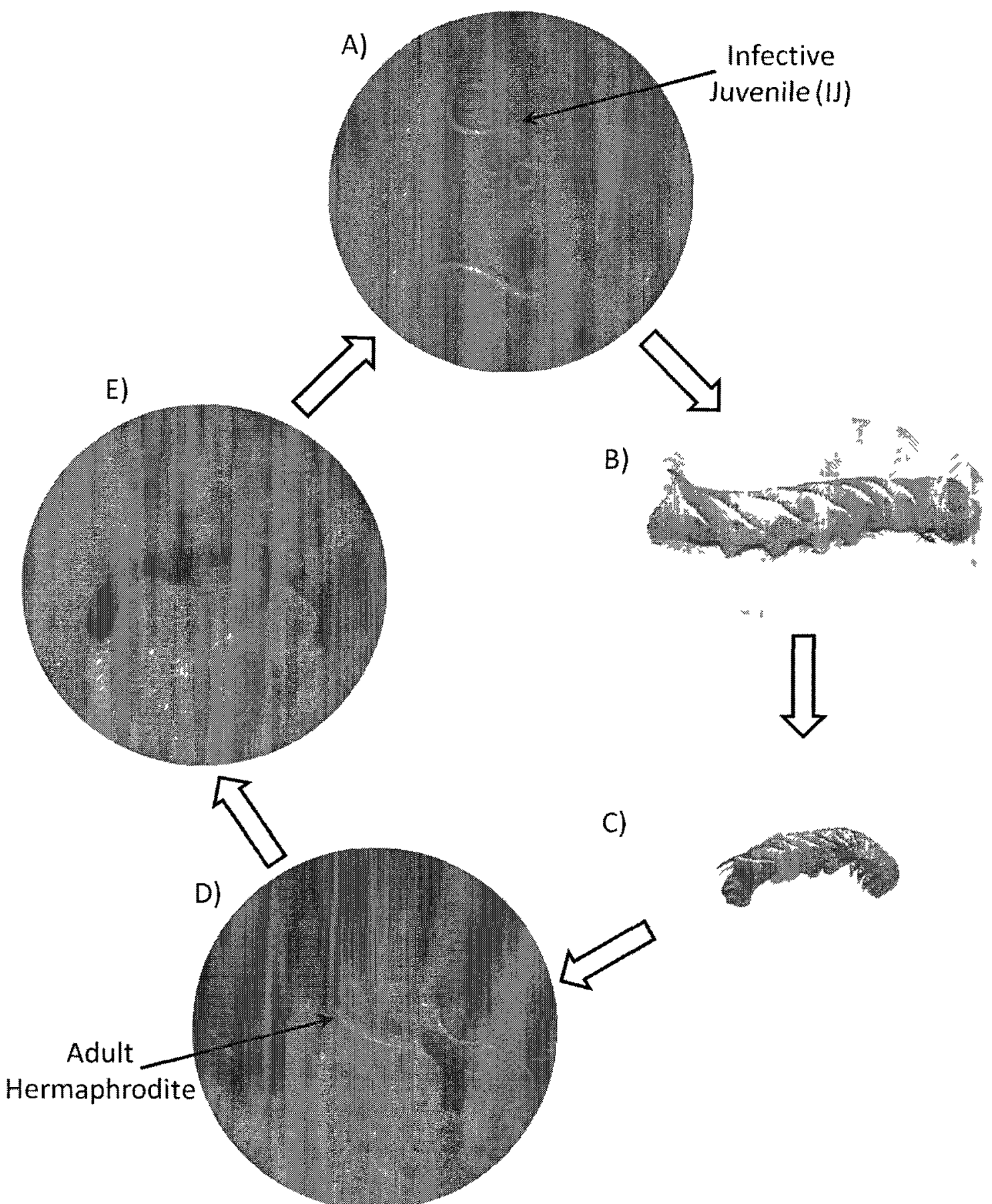

FIGURE 1. The life cycle of the Photorhabdus-Heterorhabditis association. A) Photorhabdus cells are carried symbiotically within the gut of the infective juvenile (IJ) stage of the nematode Heterorhabdits bacteriophora. B) IJs seek out and infect larval insect hosts in the soil. C) Once inside, Photorhabdus are released from the nematodes and kill the host within 48 hours and D) the IJs mature into adult hermaphroditic nematodes. E) The nematodes cycle through several generations of reproduction before taking the bacterial symbionts into their gut and exiting the cadaver. 


\section{VIRULENCE MECHANISMS}

Much like higher eukaryotic organisms, insects possess a myriad of molecular tactics for warding off infectious organisms. The insect immune system has two primary mechanisms of defense: humoral and cellular (Eleftherianos et al., 2010). Humoral immunity utilizes molecules involved in the detection and clearance of antigens, while the cellular mechanisms employ hemocytes involved in phagocytosis, foreign body encapsulation, and nodulation. Evasion of insect immune cells and antimicrobial peptides is crucial to the success of entomopathogens.

The highly virulent nature of Photorhabdus is compounded by the numerous toxins employed by this bacterium. Several groups of virulence factors have been identified as the key players in insect pathogenesis: the toxin complexes (Tcs), the "makes caterpillars floppy" toxins (Mcf), the Photorhabdus insect related proteins (Pir), and the Photorhabdus virulence cassettes (PVC) (Rodou et al., 2010).

The toxin complexes consist of four high molecular weight multisubunit complexes, Tca, Tcb, Tcc, and Tcd (Rodou et al., 2010). Toxin complex a (Tca) is the most abundant of these toxins and is highly lethal, exhibiting both oral and injectable activity (Blackburn et al., 1998; 2005). Tca works on the insect midgut, causing blebbing of the endothelium and eventual cell lysis (Blackburn et al, 1998), and is highly fatal on its own, possibly in concentrations as low as 1 part per million (Blackburn et al., 2005). RTX-like toxins have also been identified in Photorhabdus which resemble those found in Vibrio cholerae, Serratia marcescens, Erwinia tarda, and Erwinia chrysanthemi (Rodou et al., 2010). Among those are the metalloprotease PrtA, which may be involved 
in immunosuppresion (ffrench-Constant et al., 2000; Duchaud et al., 2003) and host bioconversion (Bowen et al., 2003).

There are two Mcf ("makes caterpillars floppy") toxins in Photorhabdus, Mcf1 and Mcf2 (Rodou et al., 2010). These toxins contribute to insect death by inducing apoptosis of both epithelial and phagocytic cells within the midgut (Dowling et al., 2007). Infected insects display a characteristic floppy appearance due to this cellular breakdown which becomes apparent at roughly $12 \mathrm{~h}$ post-infection, preceding death. The presence of these toxins may help enable the bacteria in the infection of different insect species (Rodou et al., 2010).

The Photorhabdus insect related (Pir) toxins, PirA and PirB, work together to confer injectable insecticidal activity (ffrench-Constant et al., 2007). PirB shares sequence similarities with $\beta$-leptinotarsin-h, a potent neurotoxin identified in the Colorado potato beetle hemolymph, as well as the pore-forming domain of $B t$ Cry toxins. These Pir toxins have the potential for use as biological control toxins, replacing the current $\mathrm{Bt}$ toxin from Bacillus thuringiensis, for which some insect resistance has emerged (Ahantarig et al., 2009).

The most recently identified class of Photorhabdus toxins are the Photorhabdus virulence cassettes (PVCs) whose precise function has yet to be identified. These PVCs are encoded by multiple copies of genes exhibiting homology to toxin genes in Serratia entomophila specifically involved in antifeeding (Yang et al., 2006; Rodou et al., 2010). In Photorhabdus, these gene products have injectable activity that work on hemocytes to assist in insect killing; however, these products do not possess any antimicrobial activity 
despite structurally resembling bacteriocins, specifically the R-type pyocins (Yang et al., 2006).

\section{HEMOLYSIN ACTIVITY AND FUNCTION}

In addition to the diverse and potent toxins secreted by Photorhabdus, the primary phase wild type cells produce erythrocyte-lysing cytolysins, termed hemolysins (Brillard et al., 2001). Hemolysins are extracellular pore-forming or cell-hydrolyzing compounds secreted by many species of bacteria, and typically function as virulence factors in vertebrate pathogens (Brillard et al., 2001; Brillard et al., 2002). Although the precise function of hemolysins in Photorhabdus infectivity is unknown, evidence from other pathogenic systems may help elucidate their role.

Serratia marcescens is both a vertebrate and invertebrate pathogen that expresses a two-partner hemolysin secretion system comprised of ShlA and ShlB (Brillard et al., 2002; Hertle, 2005). In this system, ShlA is the hemolytic protein that is transported and activated by an outer membrane protein, ShlB. A similarly dependent two-partner secretion system has been identified in Photorhabdus luminescens, comprised of phlA and $p h l B$, which contain sequence similarities with the $S$. marcescens hemolysin loci shlA and $s h l B$, respectively (Brillard et al., 2002). Similar products are found in $P$. temperata NC19 as well (Tisa, unpublished). Additionally, the $p h l A$ and $p h l B$ amino acid sequences share homologies with hemolysin gene products of Edwardsiella tarda, Proteus mirabilis, and Haemophilus ducreyi, and a putative hemolysin of Yersinia pestis, YhlA (Brillard et al., 2002).

Hemolytic activity is typically distinguished by the visual observation of clear halos on blood agar media, indicating erythrocyte lysis. Photorhabdus exhibits a distinct 
pattern of hemolysis, termed "annular", first observed by Farmer et al. in 1989. Annular hemolysis is characterized by a thin line of hemolysis several millimeters away from the bacterial colony's edge, but no hemolysis immediately adjacent to the colony on sheep blood agar. This pattern, however, is not entirely unique; Bacillus cereus exhibits a similar "discontinuous hemolytic pattern", caused by the BL hemolysin (Beecher and Wong, 1994; Brillard et al., 2001). In addition, continued growth of both Photorhabdus and $B$. cereus leads to eventual lysis of erythrocytes within the annular ring. Interestingly, this BL hemolysin functions as a major virulence factor of $B$. cereus, causing dermonecrotic vascular permeability (Beecher and Wong, 1994).

Numerous putative hemolysin genes have been identified in all three species of Photorhabdus. The complete genome sequence of $P$. luminescens TT01 reveals eight putative hemolysin- or hemagglutinin-related genes, including the phlBA operon (Duchaud et al., 2003). Eighteen putative hemolysin genes are present in the $P$. asymbiotica genome as well (Wilkinson et al., 2009). The currently unpublished draft genome sequence of $P$. temperata NC19 contains 24 putative genes involved in hemolysis (Tisa, unpublished; http://rast.nmpdr.org/).

Despite the evidence for numerous hemolysin genes in the Photorhabdus genomes, the identities and functions of these hemolytic compounds remain elusive. A study of the master flagellar operon flhDC in Xenorhabdus nematophilus suggested the presence of at least two types of hemolysin: one $f l h D C$-independent hemolysin that gives rise to annular ring formation and one extracellular $f l h D C$-dependent hemolysin potentially involved in cytotoxicity to insect immunocompetent cells (Givaudan and Lanois, 2000). Additionally, $f l h D C$ activity was shown to be involved in, but not required 
for, insect infectivity. This finding indicates that there may be a large array of virulence factors involved in pathogenesis, but the loss of only a few of these factors may not be detrimental to pathogenesis.

In 2001, Brillard et al. provide further evidence for the existence of two hemolysins in X. nematophila which are active at different stages of stationary phase and independently regulated (Brillard et al., 2001). These hemolysins also have different cytotoxicity against the two most prevalent types of insect immune cells, granulocytes and plasmatocytes. A hemolytic compound produced during early stationary phase is active against sheep erythrocytes and primarily toxic to granulocytes, the phagocytic immune cells. In contrast, late stationary phase cells produced a hemolysin active against rabbit erythrocytes and cytotoxic to plasmatocytes, the capsule-forming immune cells involved in the nodulation of foreign bodies. These two different cytolytic events imply a putative role of hemolysins in insect immunosuppression during infectivity with Xenorhabdus.

A study of XhlA offered additional support for the involvement of hemolysins in Xenorhabdus virulence. Disruption of xhlA in X. nematophila resulted in significantly attenuated virulence to Manduca sexta larvae, although this mutant ultimately remained lethal (Cowles and Goodrich-Blair, 2005). Further characterization of XhlA confirmed that this hemolysin is not responsible for the early cytolytic activity described by Brillard et al. (2001), as XhlA was primarily toxic to plasmatocytes. The absence of XhlA activity in culture supernatant also implies that this hemolysin remains cell-associated. Together, these data suggest that XhlA may function in virulence by assisting in immune system evasion or nutrient acquisition inside the insect. 
Although early discoveries focused on hemolytic activity in Xenorhabdus, a study on the PhlA hemolysin provided evidence for at least two hemolysins in Photorhabdus as well (Brillard et al., 2002). An insertional mutation in phlA did not cause any alterations in hemolytic phenotype when compared to the parental wild type on both horse and sheep blood agar, indicating the presence of an additional hemolysin with activity on blood agar media. A liquid hemolysis assay, however, did detect the presence of PhlA hemolytic activity. Interestingly, this assay did not display any hemolytic activity when performed with filter-sterilized bacterial supernatant only. Similarly, no hemolytic activity was detected in Photorhabdus culture supernatant during the prior study on the effect of hemolysins on insect immunocompetent cells (Brillard et al., 2001). These studies suggest that coincubation of bacteria and erythrocytes is necessary to identify PhlA hemolytic activity, and that PhlA may actually be cytotoxic to insect immune cells as well (Brillard et al., 2002).

Previous research on Photorhabdus and Xenorhabdus indicate a possible role of hemolysis in virulence; however, hemolysis may also function as an iron-scavenging mechanism during iron depletion. Primary phase $P$. luminescens displayed an increase in hemolytic activity under iron-depleted conditions compared to iron-supplemented conditions (Brillard et al., 2002), whereas the PhlA null mutant had no hemolysis in either condition. An injection assay using Spodoptera littoralis, however, showed that this PhlA mutant remained virulent, indicating that PhlA hemolytic activity is not a significant determinant of virulence in this organism. 


\section{RESEARCH AIMS AND SIGNIFICANCE}

Photorhabdus is a unique biological system because it is both an obligate symbiont of heterorhabditid nematodes and is highly pathogenic to insects. For this reason, Photorhabdus makes an excellent model organism for studying the molecular mechanisms involved in both pathogenesis and symbiosis and the relationship between these two stages of life. Another fascinating and unusual feature of this bacterium is its ability to lyse mammalian erythrocytes, a virulence factor typically associated with vertebrate pathogens (Brillard et al., 2001; Brillard et al., 2002). The absence of red blood cells in insects drives the central question of this research: What function, if any, do these hemolysins serve in the pathogenesis of this organism? Previous research, along with current knowledge of hemolysins in vertebrate pathogens, suggests a possible role in immunoevasion during insect infectivity (Brillard et al., 2001; Brillard et al., 2002; Cowles and Goodrich-Blair, 2005; Givaudan and Lanois, 2000). The main objectives of this study were to investigate the molecular mechanisms of hemolysin expression, to elucidate the role of hemolysins in Photorhabdus virulence, and to ultimately identify genes involved in pathogenesis. These objectives are outlined in Figure 2.

Previously, a primary-phase Photorhabdus temperata NC19 transposant library with 10,000 clones was constructed (Michaels, 2006) using a mini-Tn5 system previously described (Ciche et al., 2001). The first aim of this study was to screen this library via a blood agar plate assay to identify mutants displaying altered hemolytic phenotypes. The goal of identifying these mutants was to characterize them on the molecular level in order to understand the genetic elements involved in the expression, regulation, and transport mechanisms of hemolysins in Photorhabdus. 
The second major focus of this research was to investigate the genes involved in insect pathogenesis. An in vitro injection assay developed by Clarke and Dowds (1995) uses Galleria mellonella larvae to study Photorhabdus virulence. Although this procedure is too labor intensive to perform on the entire transposant library, it is effective for studying pathogenesis in a smaller group of mutants. Initial screening for hemolysis allowed for the pathogenic characterization of a subset of the library. Previously, an investigation of Photorhabdus motility mutants found that the absence of RNase II activity resulted in attenuated virulence (Rowedder, 2009). This finding offered the first evidence of RNase involvement in the regulation of pathogenesis. Virulence assays in this study served two purposes: first, to identify mutants altered in pathogenesis for further molecular characterization, and second, to investigate the potential role between hemolytic activity and pathogenesis. Ultimately, the mutants altered in both hemolysis and virulence identified in this study were the main focus for further genetic and physiological characterization. 




FIGURE 2. Experimental design for the study of hemolysis and virulence in $P$. temperata. 


\section{CHAPTER II}

\section{MATERIALS AND METHODS}

\section{BaCTERIAL STRAINS AND GROWTH CONDITIONS}

Photorhabdus temperata strain NC19 (ATCC 29304) was used as the parental wild type bacterium in all experiments throughout this study. Table 1 lists all of the strains and plasmids used in this study. Both primary $\left(1^{\circ}\right)$ and secondary $\left(2^{\circ}\right)$ phase phenotypic variants were used as controls in this study. Parental wild type cultures were grown in Luria-Bertani (LB) medium [1\% Bacto-Tryptone (Difco Laboratories, Sparks, MD), $0.5 \%$ yeast extract, $0.5 \% \mathrm{NaCl}$, and mutant cultures were grown in $\mathrm{LB}$ supplemented with kanamycin [25 $\mu \mathrm{g} / \mathrm{ml}]$.

A primary phase $P$. temperata $\mathrm{NC} 19$ mutant library was previously generated via transposon mutagenesis with the mini-Tn5 vector pUB394 (Michaels, 2006). Mutants from this library were used throughout this study. 
Table 1. Bacterial strains and plasmids used in this study

\begin{tabular}{|c|c|c|}
\hline Strain or Plasmid & Function/Characteristics & $\begin{array}{l}\text { Source or } \\
\text { Reference }\end{array}$ \\
\hline \multicolumn{3}{|l|}{$\underline{\text { Strains }}$} \\
\hline \multicolumn{3}{|l|}{ Escherichia coli } \\
\hline DH5a & General cloning strain & Lab stock \\
\hline TOP10 & General cloning strain & Invitrogen \\
\hline Micrococcus luteus & Indicator strain & Lab stock \\
\hline \multicolumn{3}{|l|}{ Photorhabdus temperata } \\
\hline NC19 (ATCC29304) $1^{\circ}$ & Primary parental wild type & Fischer-Le Saux \\
\hline NC19 (ATCC29304) $2^{\circ}$ & Secondary variant parental wild type & et al., 1999 \\
\hline 9A F6 & Early hemolysis; Kan ${ }^{\mathrm{R}}$ & Michaels, 2006 \\
\hline $10 \mathrm{~A} \mathrm{C} 11$ & Defective hemolysis; $\operatorname{Kan}^{R}$ & Michaels, 2006 \\
\hline 10A H12 & Defective hemolysis; $\mathrm{Kan}^{\mathrm{R}}$ & Michaels, 2006 \\
\hline 11A D12 & Defective hemolysis; $\operatorname{Kan}^{\mathrm{R}}$ & Michaels, 2006 \\
\hline $12 \mathrm{~A} \mathrm{G} 7$ & Defective hemolysis; $\operatorname{Kan}^{\mathrm{R}}$ & Michaels, 2006 \\
\hline $2 \mathrm{H} 12$ & Defective hemolysis; $\mathrm{Kan}^{\mathrm{R}}$ & Michaels, 2006 \\
\hline $5 \mathrm{~A} 12$ & Defective hemolysis; $\operatorname{Kan}^{\mathrm{R}}$ & Michaels, 2006 \\
\hline $22 \mathrm{~A} 2$ & Defective hemolysis; $\mathrm{Kan}^{\mathrm{R}}$ & Michaels, 2006 \\
\hline $24 \mathrm{~A} 4$ & Early hemolysis; Kan ${ }^{\mathrm{R}}$ & Michaels, 2006 \\
\hline 24 G12 & Defective hemolysis; $\operatorname{Kan}^{R}$ & Michaels, 2006 \\
\hline $26 \mathrm{C} 4$ & Delayed hemolysis; $\operatorname{Kan}^{\mathrm{R}}$ & Michaels, 2006 \\
\hline $26 \mathrm{E} 6$ & Delayed hemolysis; $\operatorname{Kan}^{\mathrm{R}}$ & Michaels, 2006 \\
\hline $27 \mathrm{G} 12$ & Early hemolysis; Kan ${ }^{R}$ & Michaels, 2006 \\
\hline $30 \mathrm{C} 6$ & Delayed hemolysis; Kan ${ }^{\mathrm{R}}$ & Michaels, 2006 \\
\hline $30 \mathrm{~F} 2$ & Delayed hemolysis; Kan ${ }^{\mathrm{R}}$ & Michaels, 2006 \\
\hline $32 \mathrm{C} 5$ & Delayed hemolysis; Kan ${ }^{\mathrm{R}}$ & Michaels, 2006 \\
\hline $35 \mathrm{~B} 9$ & Early hemolysis; $\mathrm{Kan}^{\mathrm{R}}$ & Michaels, 2006 \\
\hline $32 \mathrm{E} 4$ & Delayed hemolysis; $\operatorname{Kan}^{\mathrm{R}}$ & Michaels, 2006 \\
\hline $34 \mathrm{E} 2$ & Delayed hemolysis; $\operatorname{Kan}^{\mathrm{R}}$ & Michaels, 2006 \\
\hline $36 \mathrm{C} 10$ & Defective hemolysis; $\operatorname{Kan}^{\mathrm{R}}$ & Michaels, 2006 \\
\hline $36 \mathrm{D} 3$ & Early hemolysis; Kan ${ }^{\mathrm{R}}$ & Michaels, 2006 \\
\hline 36 D6 & Delayed hemolysis; $\operatorname{Kan}^{\mathrm{R}}$ & Michaels, 2006 \\
\hline $37 \mathrm{C} 1$ & Defective hemolysis; $\operatorname{Kan}^{\mathrm{R}}$ & Michaels, 2006 \\
\hline $37 \mathrm{C} 5$ & Delayed hemolysis; $\operatorname{Kan}^{\mathrm{R}}$ & Michaels, 2006 \\
\hline $38 \mathrm{~A} 10$ & Delayed hemolysis; $\operatorname{Kan}^{\mathrm{R}}$ & Michaels, 2006 \\
\hline $38 \mathrm{C} 10$ & Early hemolysis; Kan ${ }^{R}$ & Michaels, 2006 \\
\hline 38 D10 & Defective hemolysis; $\operatorname{Kan}^{\mathrm{R}}$ & Michaels, 2006 \\
\hline 38 E11 & Defective hemolysis; $\operatorname{Kan}^{\mathrm{R}}$ & Michaels, 2006 \\
\hline $38 \mathrm{G} 3$ & Early hemolysis; $\operatorname{Kan}^{\mathrm{R}}$ & Michaels, 2006 \\
\hline 40 D10 & Defective hemolysis; $\operatorname{Kan}^{\mathrm{R}}$ & Michaels, 2006 \\
\hline $40 \mathrm{E} 6$ & Delayed hemolysis; $\operatorname{Kan}^{\mathrm{R}}$ & Michaels, 2006 \\
\hline $40 \mathrm{E} 7$ & Defective hemolysis; $\operatorname{Kan}^{\mathrm{R}}$ & Michaels, 2006 \\
\hline
\end{tabular}


Table 1 (cont.)

\begin{tabular}{|c|c|c|}
\hline Strain or Plasmid & Function/Characteristics & $\begin{array}{l}\text { Source or } \\
\text { Reference } \\
\end{array}$ \\
\hline $41 \mathrm{~B} 3$ & Defective hemolysis; $\operatorname{Kan}^{\mathrm{K}}$ & Michaels, 2006 \\
\hline $41 \mathrm{D} 5$ & Delayed hemolysis; $\mathrm{Kan}^{\mathrm{R}}$ & Michaels, 2006 \\
\hline $46 \mathrm{G} 6$ & Defective hemolysis; $\operatorname{Kan}^{\mathrm{R}}$ & Michaels, 2006 \\
\hline 47 H6 & Defective hemolysis; $\mathrm{Kan}^{\mathrm{R}}$ & Michaels, 2006 \\
\hline $50 \mathrm{C} 5$ & Defective hemolysis; $\operatorname{Kan}^{\mathrm{R}}$ & Michaels, 2006 \\
\hline $51 \mathrm{F9}$ & Defective hemolysis; $\mathrm{Kan}^{\mathrm{R}}$ & Michaels, 2006 \\
\hline $53 \mathrm{H} 3$ & Defective hemolysis; $\operatorname{Kan}^{\mathrm{R}}$ & Michaels, 2006 \\
\hline $56 \mathrm{H} 7$ & Defective hemolysis; $\mathrm{Kan}^{\mathrm{R}}$ & Michaels, 2006 \\
\hline $59 \mathrm{G} 4$ & Delayed hemolysis; $\mathrm{Kan}^{\mathrm{R}}$ & Michaels, 2006 \\
\hline 59 G6 & Early hemolysis; Kan ${ }^{\mathrm{R}}$ & Michaels, 2006 \\
\hline $60 \mathrm{~A} 2$ & Defective hemolysis; $\operatorname{Kan}^{\mathrm{R}}$ & Michaels, 2006 \\
\hline $61 \mathrm{E} 8$ & Early hemolysis; $\mathrm{Kan}^{\mathrm{R}}$ & Michaels, 2006 \\
\hline $62 \mathrm{~A} 7$ & Delayed hemolysis; $\operatorname{Kan}^{\mathrm{R}}$ & Michaels, 2006 \\
\hline $65 \mathrm{~B} 5$ & Defective hemolysis; $\operatorname{Kan}^{\mathrm{R}}$ & Michaels, 2006 \\
\hline $65 \mathrm{C} 10$ & Defective hemolysis; $\operatorname{Kan}^{\mathrm{R}}$ & Michaels, 2006 \\
\hline $65 \mathrm{D} 5$ & Delayed hemolysis; $\operatorname{Kan}^{\mathrm{R}}$ & Michaels, 2006 \\
\hline $67 \mathrm{H} 1$ & Delayed hemolysis; $\operatorname{Kan}^{\mathrm{R}}$ & Michaels, 2006 \\
\hline $69 \mathrm{D} 1$ & Defective hemolysis; $\operatorname{Kan}^{\mathrm{R}}$ & Michaels, 2006 \\
\hline $69 \mathrm{H} 6$ & Delayed hemolysis; $\operatorname{Kan}^{\mathrm{R}}$ & Michaels, 2006 \\
\hline $71 \mathrm{H} 4$ & Defective hemolysis; $\operatorname{Kan}^{\mathrm{R}}$ & Michaels, 2006 \\
\hline $72 \mathrm{C} 12$ & Defective hemolysis; $\mathrm{Kan}^{\mathrm{R}}$ & Michaels, 2006 \\
\hline 72 F9 & Delayed hemolysis; $\mathrm{Kan}^{\mathrm{R}}$ & Michaels, 2006 \\
\hline $78 \mathrm{E} 3$ & Defective hemolysis; $\operatorname{Kan}^{\mathrm{R}}$ & Michaels, 2006 \\
\hline $79 \mathrm{~B} 5$ & Defective hemolysis; $\operatorname{Kan}^{\mathrm{R}}$ & Michaels, 2006 \\
\hline $79 \mathrm{G} 12$ & Defective hemolysis; $\operatorname{Kan}^{\mathrm{R}}$ & Michaels, 2006 \\
\hline $80 \mathrm{~A} 11$ & Defective hemolysis; $\operatorname{Kan}^{\mathrm{R}}$ & Michaels, 2006 \\
\hline $81 \mathrm{C} 4$ & Defective hemolysis; $\operatorname{Kan}^{\mathrm{R}}$ & Michaels, 2006 \\
\hline $81 \mathrm{E} 2$ & Defective hemolysis; $\operatorname{Kan}^{\mathrm{R}}$ & Michaels, 2006 \\
\hline $81 \mathrm{~F} 5$ & Defective hemolysis; $\operatorname{Kan}^{\mathrm{R}}$ & Michaels, 2006 \\
\hline $82 \mathrm{~A} 12$ & Defective hemolysis; $\mathrm{Kan}^{\mathrm{R}}$ & Michaels, 2006 \\
\hline $82 \mathrm{~B} 11$ & Defective hemolysis; $\operatorname{Kan}^{\mathrm{R}}$ & Michaels, 2006 \\
\hline $82 \mathrm{D} 2$ & Defective hemolysis; $\operatorname{Kan}^{\mathrm{R}}$ & Michaels, 2006 \\
\hline $82 \mathrm{H} 12$ & Early hemolysis; $\operatorname{Kan}^{\mathrm{R}}$ & Michaels, 2006 \\
\hline $83 \mathrm{~A} 1$ & Defective hemolysis; $\mathrm{Kan}^{\mathrm{R}}$ & Michaels, 2006 \\
\hline $83 \mathrm{E} 1$ & Defective hemolysis; $\operatorname{Kan}^{\mathrm{R}}$ & Michaels, 2006 \\
\hline $84 \mathrm{E} 1$ & Defective hemolysis; $\operatorname{Kan}^{\mathrm{R}}$ & Michaels, 2006 \\
\hline $84 \mathrm{H} 11$ & Defective hemolysis; $\mathrm{Kan}^{\mathrm{R}}$ & Michaels, 2006 \\
\hline $86 \mathrm{C} 7$ & Early hemolysis; $\operatorname{Kan}^{\mathrm{R}}$ & Michaels, 2006 \\
\hline $86 \mathrm{G} 2$ & Delayed hemolysis; $\operatorname{Kan}^{\mathrm{R}}$ & Michaels, 2006 \\
\hline 89 F5 & Defective hemolysis; $\operatorname{Kan}^{\mathrm{R}}$ & Michaels, 2006 \\
\hline
\end{tabular}


Table 1 (cont.)

\begin{tabular}{clc} 
Strain or Plasmid & Function/Characteristics & $\begin{array}{c}\text { Source or } \\
\text { Reference }\end{array}$ \\
\hline 90 B9 & Defective hemolysis; Kan ${ }^{\mathrm{R}}$ & Michaels, 2006 \\
90 E2 & Defective hemolysis; Kan ${ }^{\mathrm{R}}$ & Michaels, 2006
\end{tabular}

$\underline{\text { Plasmids }}$ pUB384 mini-Tn5 delivery vector; $\mathrm{Kan}^{\mathrm{R}}, \mathrm{Str}^{\mathrm{R}}, \mathrm{Spec}^{\mathrm{R}} \quad$ Ciche et al., 2001 


\section{HEMOLYSIS ASSAY TO IDENTIFY MUTANTS ALTERED IN HEMOLYTIC ABILITY}

The transposon mutant library was screened for hemolysis activity on blood agar plates (Figure 3). Blood agar medium was composed of T-soy [3\% Tryptic Soy Broth (EM Science, Darmstadt, Germany), 2\% Bacto-Agar (Difco Laboratories)] supplemented with sheep's blood [5\%,v:v]. For the screening experiments, blood agar medium was poured into oversized petri dishes $(150 \times 15 \mathrm{~mm}$; Fisher Scientific, Canada). The mutant library was stored at $-80^{\circ} \mathrm{C}$ in a collection of 96 -well microtiter plates as previously described (Michaels, 2006). Using a $96-$ well replicator, the $-80^{\circ} \mathrm{C}$ stored transposants were transferred into 96-well microtiter plates containing fresh LB medium with kanamycin and incubated overnight at $28^{\circ} \mathrm{C}$. The freshly grown overnight culture was replica plated directly onto the oversized blood agar plates. Two $\mu 1$ of the primary and secondary phase parental wild type cells were spotted on each plate as controls. Plates were incubated at $28^{\circ} \mathrm{C}$ and observed at 24,48 , and $72 \mathrm{~h}$ for hemolytic patterns. Criteria for determining altered hemolytic activity were time-dependent. Putative mutants displayed early, delayed, or defective hemolysis when compared to the primary parental wild type which exhibited hemolysis between 19 and $24 \mathrm{~h}$. Preliminary mutants identified as altered in their hemolytic pattern were purified by isolation streaks and retested at least 3 times. For these cultures, $2 \mu \mathrm{l}$ of each overnight broth culture including the primary and secondary wild type controls were spot inoculated onto the surface of blood agar plates and incubated for $72 \mathrm{~h}$. Hemolytic activity was monitored every $24 \mathrm{~h}$. Confirmed mutants were purified by streaking on LB agar containing kanamycin. A single colony was inoculated into LB broth and grown overnight. Cells were suspended in $30 \%$ glycerol and stored at $-80^{\circ} \mathrm{C}$ for further study. 


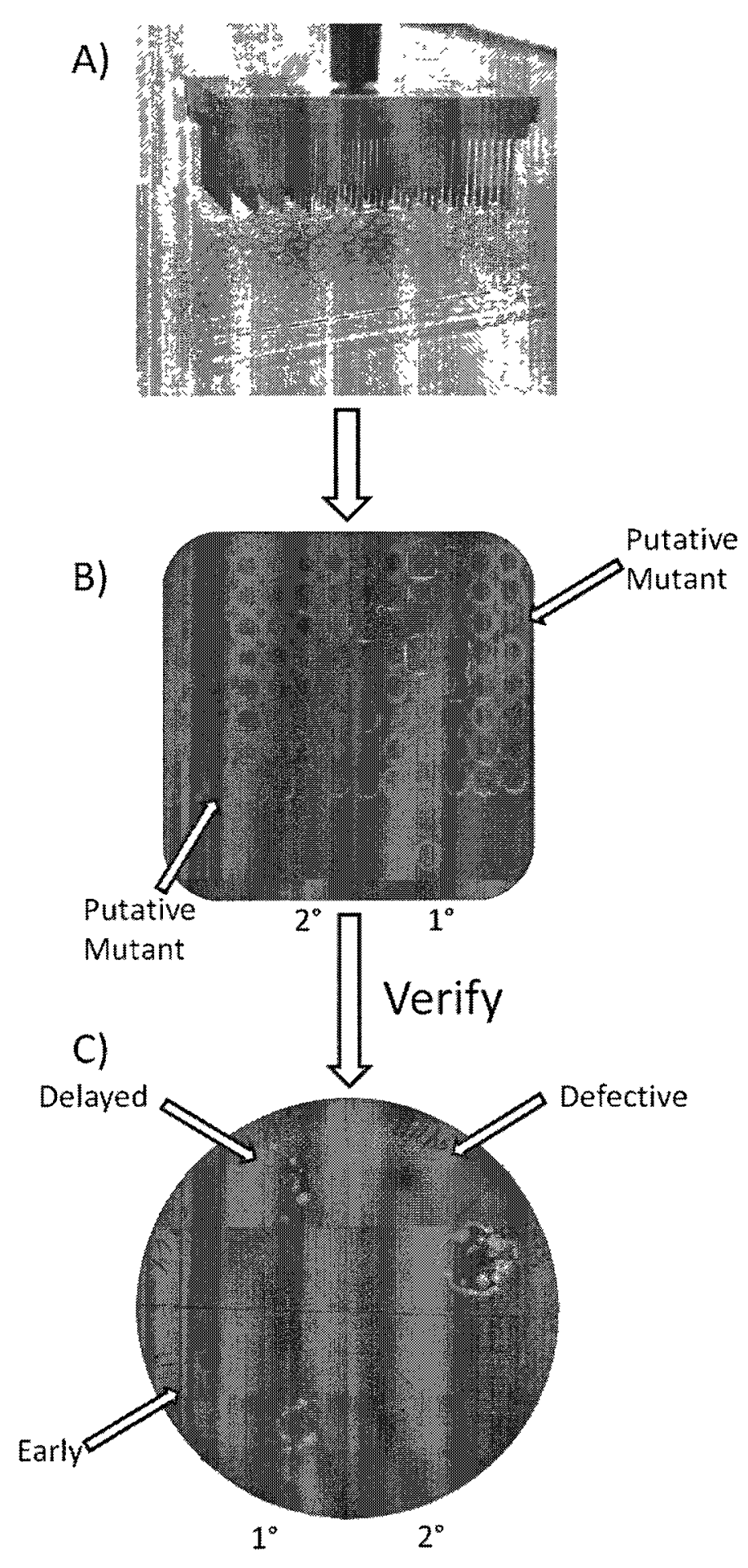

Figure 3. Hemolysis plate assay for the screening and identification of hemolytic mutants. A) Overnight grown cultures in 96-well plates were spot inoculated onto sheep blood agar plates by the use of a pin replicator and incubated at $28^{\circ} \mathrm{C}$. B) Hemolytic activity was observed at 24,48 , and $72 \mathrm{~h}$ post-incubation. C) Putative hemolytic mutants were subcultured and $2 \mu \mathrm{l}$ of each overnight culture was spot inoculated onto blood agar plates for verification. 


\section{IN Vitro Insect Pathogenesis Assay}

Insect pathogenesis was assessed by a modified method of Clarke and Dowds (1995) and used the greater wax moth larvae, Galleria mellonella, (Grubco, Inc. Hamilton, $\mathrm{OH}$ ) as the host (Figure 4). Prior to use larvae were stored at room temperature in wood shavings for up to two weeks. Bacterial cultures were grown in LB broth overnight at $28^{\circ} \mathrm{C}$ with agitation and optical density of the culture was measured with a Shimadzu UV-2401 PC spectrophotometer (Norwell, MA). Cultures were diluted to an $\mathrm{OD}_{600}$ of 1.0 and subsequently serially diluted. Ten $\mu \mathrm{l}$ of the $10^{-5}$ dilution (approximately 100 cells) were injected directly into the hemocoel of 20 larvae. Controls consisted of primary and secondary parental wild type cells and sterile LB medium (no cells; negative control). Insect mortality was monitored regularly for $60 \mathrm{~h}$ and the lethal time required to kill half of the larvae $\left(\mathrm{LT}_{50}\right)$ and all of the larvae $\left(\mathrm{LT}_{100}\right)$ was determined. Mutants displaying $\mathrm{LT}_{50}$ or $\mathrm{LT}_{100}$ that differed by greater than $10 \mathrm{~h}$ from the parental wild type values were considered to have an enhanced $(\leq 10 \mathrm{~h})$ or delayed $(\geq 10 \mathrm{~h})$ pathogenesis response. To obtain a viable cell count for each inoculum, $10 \mu l$ of the injected dilution was spread plated onto LB agar containing $10 \%$ pyruvate (supplemented with kanamycin for mutant cultures) and incubated at $28^{\circ} \mathrm{C}$ overnight. A multiplicity of infection (MOI) assay was used to confirm that the altered virulence observed in putative pathogenesis mutants was not dose-dependent. This assay tested cultures at four dilutions and was performed as previously described, using $10 \mu \mathrm{l}$ culture from the $10^{-2}$ through $10^{-5}$ dilutions. These dilutions corresponded to infective doses ranging from 10,000 to 10 cells, respectively. As before, insect health was monitored for $60 \mathrm{~h}$ and compared to the corresponding primary parental wild type dosage. 


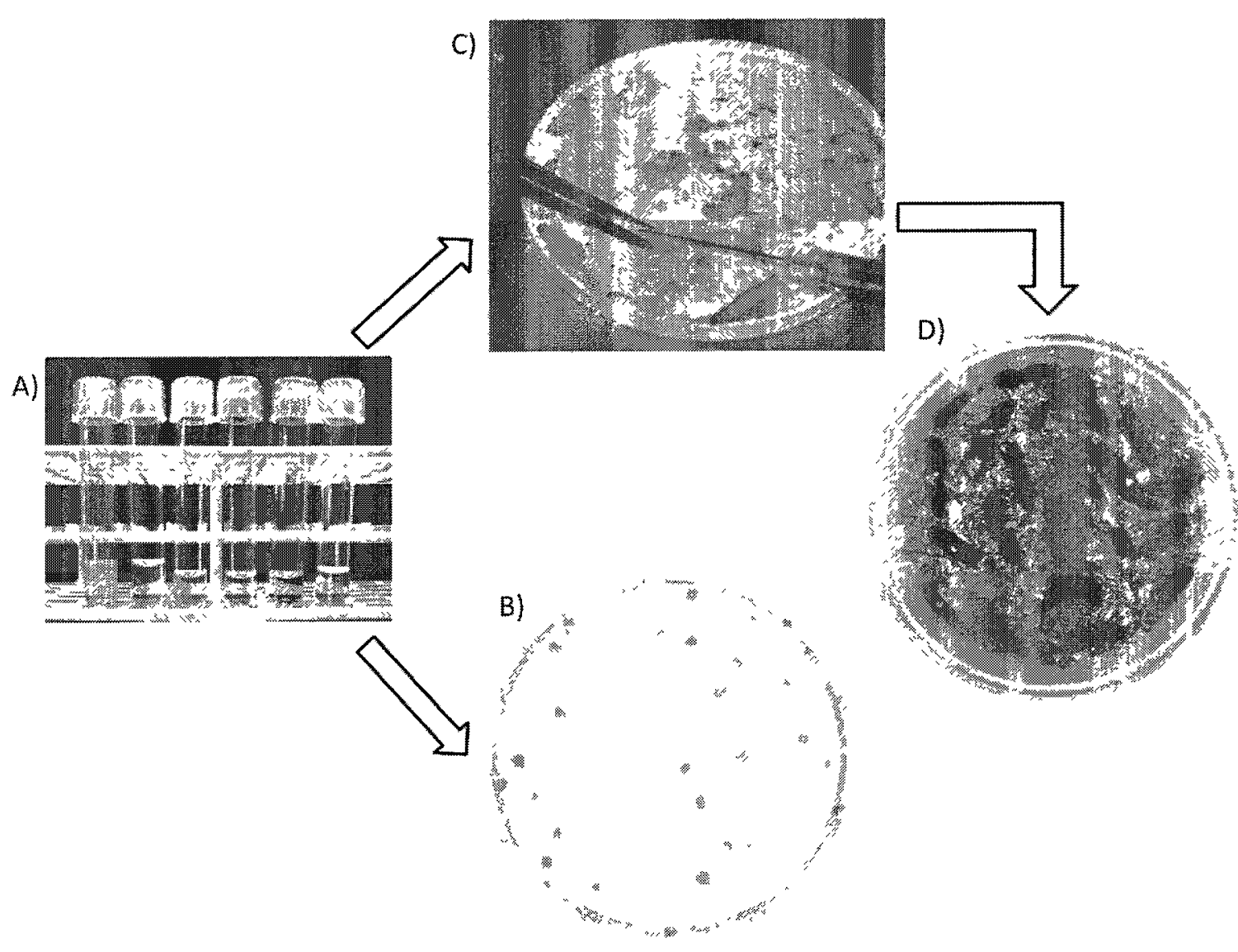

FIGURE 4. In vitro insect pathogenesis assay. A) Overnight cultures were standardized to an $\mathrm{OD}_{600}$ of 1.0 and serially diluted 10 -fold. B) Viable counts were obtained by spread plating $10 \mu \mathrm{l}$ of each dilution onto LB agar containing pyruvate. C) For each Galleria mellonella larva, $10 \mu 1$ of the appropriate dilution was injected into the hemocoel and 20 larvae in total were injected for each sample. D) Insect mortality was monitored over a 60 $\mathrm{h}$ time period. 


\section{PHYSIOLOGICAL ASSAYS}

Phenotypic properties of the mutants were determined by the use of standard plate assays for virulence factors and dye binding as described previously (Hodgson et al., 2003).

\section{DYE BINDING}

Bacteria were streaked onto the following four growth media containing dyes: (1) MacConkey agar (Difco Laboratories), (2) EMB [2\% Proteose Peptone 3 (Remel, Lenexa, KS), 2\% Bacto-Agar, 0.04\% Eosin Y, 0.0067\% Methylene Blue], (3) NBTA [2.3\% Nutrient Agar (Difco Laboratories), 0.0025\% Bromothymol Blue, 0.004\% triphenyl-tetrazolium chloride (TTC)] and (4) LB agar containing calcofluor dye $(0.02$ $\mathrm{mg} / \mathrm{ml}$ ). For Photorhabdus, the first three indicator media are primarily used to determine phase variation (Boemare et al., 1997; Hodgson et al., 2003). Inoculated media were incubated at $28^{\circ} \mathrm{C}$ for $72 \mathrm{~h}$. Primary phase parental wild type cells form red colonies on MacConkey, while secondary phase colonies appear light orange or pink. On EMB medium, primary phase colonies appear shiny metallic green, while secondary phase colonies are opaque purple. Primary phase colonies on NBTA medium display a dark green color, while secondary phase colonies are lighter green and pink. Secondary phase colonies will bind the fluorescent dye, calcofluor, and will fluoresce under UV light. The primary phase cultures do not bind the calcofluor dye and do not fluoresce under UV light.

\section{PROTEASE ASSAYS}

Besides dye binding, mutants were screened for altered phenotypes involving secreted products. To assess protease activity, $2 \mu 1$ of overnight culture was spotted onto 
gelatin plates $[2.3 \%$ Nutrient Agar (Difco Laboratories), $1.2 \%$ gelatin (Difco Laboratories)] and the radii of clearing zones were measured in $\mathrm{mm}$ at 24 and $48 \mathrm{~h}$ and compared to the zones of the primary and secondary parental wild types. At $48 \mathrm{~h}$, a halo greater than $2 \mathrm{~mm}$ was designated positive $(+)$, a halo with a radius of less than $2 \mathrm{~mm}$ was designated intermediate $(+/-)$, and the absence of any clearing zone was noted as negative (-).

\section{LIPASE ASSAYS}

Primary phase Photorhabdus secretes lipase extracellularly. To test for lipase production in mutants, $2 \mu$ l of overnight culture was spotted onto Spirit Blue agar [3.5\% Spirit Blue Agar (Difco Laboratories), 3\% (v:v) Bacto-Lipase Reagent (Difco Laboratories)]. Primary phase parental wild type exhibits a halo around the colony after $48 \mathrm{~h}$ incubation at $28^{\circ} \mathrm{C}$, while the secondary phase wild type does not. Mutant cultures displaying a halo with radius greater than $1 \mathrm{~mm}$ were noted as positive $(+)$ while the absence of a halo was designated negative (-).

\section{DNASE ASSAYS}

DNase activity of pathogenesis mutants was assessed by spot-inoculating $2 \mu \mathrm{l}$ overnight culture onto DNase plates containing methyl green (Difco Laboratories) and incubated at $28^{\circ} \mathrm{C}$. The primary parental wild type produces a $2 \mathrm{~mm}$ halo of clearing at 48 $\mathrm{h}$, indicating DNA degradation, while the secondary wild type produces a $1 \mathrm{~mm}$ zone. The radii of clearing zones produced by mutants were measured at 24 and $48 \mathrm{~h}$ incubation. 


\section{ANTIMICROBIAL ASSAYS}

Antimicrobial activity was assessed by the agar plug method. Cultures were grown to confluency on Proteose Peptone 3 agar [2\% Proteose Peptone 3 (Remel), 2\% Bacto-Agar, $0.5 \% \mathrm{NaCl}$ for $72 \mathrm{~h}$ at $28^{\circ} \mathrm{C}$ and 5 -mm-diameter plugs were extracted. The plugs were placed onto the surface of LB plates inoculated with an overnight culture of Micrococcus luteus. Plates were incubated overnight at $37^{\circ} \mathrm{C}$ and zones of inhibition were recorded in $\mathrm{mm}$ (radius).

\section{SIDEROPHORE ASSAYS}

To assess siderophore production in hemolysis mutants, $2 \mu \mathrm{l}$ of an overnight culture was spot-inoculated onto Chrome Azurol S agar (CAS) (Schwyn and Neilands, 1987) and incubated at $28^{\circ} \mathrm{C}$. The radii of resulting halos were measured in $\mathrm{mm}$. An orange halo greater than $2 \mathrm{~mm}$ surrounding the colonies after $48 \mathrm{~h}$ incubation indicated positive siderophore production $(+)$, a radius of less than $2 \mathrm{~mm}$ was designated intermediate production $(+/-)$, and the absence of a halo denoted negative siderophore production (-).

\section{MOTILITY ASSAYS}

Motility in the form of swimming and swarming was assessed for all hemolysis mutants. Swimming motility (movement through liquid) was assayed as previously described (Hodgson, 2003). Briefly, overnight culture was stab-inoculated into the center of swim medium [ $1 \%$ peptone (Difco Laboratories), $1 \%$ yeast extract, $0.5 \% \mathrm{NaCl}, 0.25 \%$ Bacto-Agar] and the diameter of swim rings were measured (mm) after 24 and $48 \mathrm{~h}$ incubation at $28^{\circ} \mathrm{C}$. Swarming motility (surface movement) was assayed as previously described (Michaels and Tisa, 2011). Briefly, $2 \mu$ overnight liquid culture was spotinoculated onto the surface of PP3-swarm medium [2\% Proteose Peptone 3, 0.5\% yeast 
extract, $0.5 \% \mathrm{NaCl}, 0.65 \%$ Bacto-agar] and the diameter of swarm rings was measured (mm) after 24 and $48 \mathrm{~h}$ incubation at $28^{\circ} \mathrm{C}$.

\section{GROWTH ASSAYS}

Cultures were grown overnight in $\mathrm{LB}$ broth and subsequently diluted to $\mathrm{OD}_{595}$ of 0.1 in fresh LB medium without kanamycin. Diluted cultures $(200 \mu \mathrm{l})$ were inoculated into sterile 96-well polystyrene microtiter plates. The inoculated plates were placed into a Tecan plate reader with Magellan software (Tecan Group Ltd., Switzerland) and incubated at $28^{\circ} \mathrm{C}$ with shaking. The $\mathrm{OD}_{595}$ was measured every half hour for a $24-\mathrm{h}$ period. The average and standard deviation of each sample was determined from the replicate wells $(\mathrm{n}=6)$ and these values were plotted versus time. The doubling times were determined for the mutants and the primary and secondary parental wild types.

\section{QUANTITATIVE HEMOLYSIS ASSAY}

Confirmed virulence mutants were further assayed for hemolytic activity using a quantitative liquid hemolysis assay modified from Hertle et al. (1999), and from Ondraczek et al. (1992). For each mutant, a 48-h liquid culture was assessed for hemolytic activity with (1) filter-sterilized culture supernatant, (2) bacterial cells washed with PBS [137 mM NaCl, $2.7 \mathrm{mM} \mathrm{KCl}, 10 \mathrm{mM}$ phosphate buffer, pH 7.3-7.5 (EM Science)], and (3) whole-culture suspension in LB broth. Primary and secondary parental wild type cultures were used for comparative purposes, while $10 \%$ sodium dodecyl sulfate (SDS) served as a positive control and LB as a negative control. For each sample and controls, $100 \mu$ sample was added to $1 \mathrm{~mL}$ washed $10 \%$ sheep erythrocytes in PBS and incubated with agitation at $28^{\circ} \mathrm{C}$ for $4 \mathrm{~h}$. Absorbance $\left(\mathrm{A}_{405}\right)$ was measured every hour and hemolytic activity was calculated using the formula $\left[\left(\mathrm{A}_{405}\right.\right.$ Sample $-\mathrm{A}_{405}$ Negative 
control)/ $\mathrm{A}_{405}$ Positive control] X $100=$ Hemolytic Units. Hemolytic units were plotted versus time to assess the hemolytic activity of each sample for each mutant compared to the primary and secondary parental wild types.

\section{MOLECULAR CHARACTERIZATION}

Genomic DNA (gDNA) was extracted by the cetyltrimethylammonium bromide (CTAB) method (Murray and Thompson, 1980) and DNA yield and purity were determined using the NanoDrop 2000c spectrophotometer (Thermo Scientific, Wilmington, DE).

The transposon and flanking DNA regions were recovered using a rescue cloning protocol (Ciche et al., 2001). Ten $\mu$ g genomic DNA was digested overnight with $10 \mathrm{U}$ $N_{s i}$ (New England BioLabs Inc., Ipswich, MA) and subsequently self-ligated using $10 \mathrm{U}$ T4 DNA ligase (New England BioLabs Inc.) and $50 \mu \mathrm{l} 44$ DNA Ligase Reaction Buffer $(10 \mathrm{X})$ in a $500 \mu \mathrm{l}$ reaction at room temperature overnight. Ligated plasmids were electroporated into E. coli DH5a using an E. coli Pulser (Bio-Rad Laboratories, Hercules, CA). Electrocompetent DH5 $\alpha$ were prepared by subculturing overnight culture in LB broth, growing to $\mathrm{OD}_{600} 0.5-0.7$, and performing three washes with ice-cold $1 \mathrm{mM}$ HEPES \{2-[4-(2-Hydroxyethyl)-1-piperazine]ethanesulfonic acid, Acros Organics, New Jersey\} at $4^{\circ} \mathrm{C}$ before storing cells in $10 \%$ glycerol at $-80^{\circ} \mathrm{C}$. After electroporation, transformed cells were recovered in SOC medium (2\% tryptone, $0.5 \%$ yeast extract, $0.058 \% \mathrm{NaCl}, 0.019 \% \mathrm{KCl}, 0.2 \% \mathrm{MgCl}_{2} \cdot 6 \mathrm{H}_{2} \mathrm{O}, 0.49 \% \mathrm{MgSO}_{4} \cdot 7 \mathrm{H}_{2} \mathrm{O}, 0.36 \%$ glucose) for $2 \mathrm{~h}$ at $37^{\circ} \mathrm{C}$ before plating on LB agar supplemented with kanamycin. Plates were grown overnight at $37^{\circ} \mathrm{C}$ and resulting colonies were analyzed for the presence of plasmid. 
Recovered plasmids were isolated by the use of the QIAprep ${ }^{\circledR}$ Spin Miniprep Kit

(Qiagen Inc., Valencia, CA) according to manufacturer's instructions. Genetic material flanking the transposon was sequenced using primer M13R-27 (Table 2) and performed at the Hubbard Center for Genome Studies at the University of New Hampshire (Durham, $\mathrm{NH})$. Sequence was analyzed using the $P$. temperata genome available on RAST [http://rast.nmpdr.org, (Aziz et al., 2008)] and P. luminescens and P. asymbiotica genomes available on NCBI's BLAST program (http://blast.ncbi.nlm.nih.gov/Blast.cgi).

\section{RESTRICTION FRAGMENT LENGTH POLYMORPHISM}

Mutants of interest displaying markedly unusual characteristics were analyzed to confirm that they were Photorhabdus cultures and not contaminating organisms. Polymerase chain reaction (PCR) of the $16 \mathrm{~S}$ gene region was performed on mutant and primary parental wild type gDNA $(\sim 150 \mathrm{ng})$ using primers $27 \mathrm{~F}$ and $1492 \mathrm{R}(10 \mu \mathrm{M})$ (Table 2). Thermal cycling parameters included initial denaturation at $94^{\circ} \mathrm{C}$ for $2 \mathrm{~min}$, followed by 35 cycles of denaturation for $30 \mathrm{sec}\left(94^{\circ} \mathrm{C}\right)$, primer annealing for $30 \mathrm{sec}$ $\left(54^{\circ} \mathrm{C}\right)$, and extension for $90 \sec \left(68^{\circ} \mathrm{C}\right)$, followed by a final elongation for $5 \mathrm{~min}$ at $68^{\circ} \mathrm{C}$. PCR product was purified using the QIAquick $\mathbb{B}$ PCR Purification Kit (Qiagen Inc.) and digested with 10 U HaeIII (New England BioLabs Inc.) according to manufacturer's instructions. Digested DNA was electrophoresed on $2 \%$ agarose in $1 \mathrm{X}$ TAE $(40 \mathrm{mM}$ Tris-acetate, $1 \mathrm{mM}$ EDTA, $\mathrm{pH}$ 8.1-8.5). Fragment sizes of each mutant were compared to the primary parental wild type. 
Table 2. Primers used in this study

\begin{tabular}{|c|c|c|c|c|c|}
\hline & \multicolumn{2}{|l|}{ Primer } & Primer set $\left(5^{\prime}-3^{\prime}\right)$ & Gene & Reference \\
\hline & $27 \mathrm{~F}$ & $\mathrm{~F}$ & AGA GTT TGA TCA TGG CTC AG & Universal $16 \mathrm{~S}$ rRNA & Weisburg et al., 1991 \\
\hline & $1492 \mathrm{R}$ & $\mathrm{R}$ & ACG GCT ACC TTG TTA CGA CTT & Universal 16S rRNA & Weisburg et al., 1991 \\
\hline & HCP Set 5 & $\mathrm{R}$ & CCT GCG ATA AGG TGA TTC CAG GTA & pte4665 (RT-PCR) & This study \\
\hline & M13F (-20) & $\mathrm{F}$ & GTA AAA CGA CGG CCA GTG & mini-Tn5 & Michaels, 2006 \\
\hline & PT-KAN-F & $\mathrm{F}$ & GTA AAC TGG ATG GCT TTC TTG CCG & Kanamycin resistance & Michaels, 2006 \\
\hline & PT-KAN-R & $\mathrm{R}$ & ATA TCA CGG GTA GCC AAC GCT ATC & gene of pUB394 & Michaels, 2006 \\
\hline 岩 & Pte3807 Set 5 & $\mathrm{~F}$ & ATT CGC CAG CTT ACA GGA TGC CTA & pte3807 (PCR/RT-PCR) & This study \\
\hline & Pte3807 Set 5 & $\mathrm{R}$ & TCG CTG ATA GGC ATG TAA GGC AGT & pte3807 (PCR/RT-PCR) & This study \\
\hline
\end{tabular}




\section{CONFIRMATION OF TRANSPOSON INSERTION SITES}

To confirm the location of transposon insertion in the genome, a PCR approach was used. Primers $(10 \mu \mathrm{M})$ designed for reverse transcription PCR (Table 2) were used to amplify genes of interest from approximately $100 \mathrm{ng}$ mutant and wild type gDNA. DNA regions containing the inserted transposon yielded products approximately $2.5 \mathrm{~kb}$ larger than the expected product size when compared to the primary parental wild type products. Cycling parameters included an initial denaturation at $94^{\circ} \mathrm{C}$ for $5 \mathrm{~min}$, followed by 35 cycles of denaturation for $30 \sec \left(94^{\circ} \mathrm{C}\right)$, primer annealing for $30 \sec \left(58^{\circ} \mathrm{C}\right)$, and extension for $3.5 \mathrm{~min}\left(72^{\circ} \mathrm{C}\right)$, followed by a final elongation for $10 \mathrm{~min}$ at $72^{\circ} \mathrm{C}$. Amplified product was subjected to electrophoresis in a $2 \%$ agarose matrix in $1 \mathrm{X}$ TAE buffer and visualized by ethidium bromide staining.

\section{RNA EXTRACTION}

RNA was extracted from mutants of interest and parental wild type cultures. Overnight cultures were subcultured in fresh $\mathrm{LB}$ and grown to $\mathrm{OD}_{600} \sim 0.7$ before harvesting $500 \mu \mathrm{l}$ using the Qiagen RNAprotect ${ }^{\mathrm{TM}}$ Bacteria Reagent and Qiagen RNeasy ${ }^{\circledR}$ Protect Bacteria Mini Kit according to manufacturer's instructions (Qiagen Inc.). RNA was eluted from the spin column membrane using $50 \mu 1$ RNase-free water. For purification of RNA samples, 1X DNase I Reaction Buffer (New England BioLabs Inc.), 5 U DNase I (New England BioLabs Inc.), 200 U RNaseOUTTM Recombinant Ribonuclease Inhibitor (Invitrogen Corporation, Carlsbad, CA), and DEPC-treated water were added to the $50 \mu \mathrm{RNA}$ samples to a final volume of $100 \mu 1$. Samples were incubated for $30 \mathrm{~min}$ at $37^{\circ} \mathrm{C}$ before inactivation of the DNase I with $1 \mu$ l $0.5 \mathrm{M}$ EDTA, 
pH 8.0 (Ambion Inc., Austin, TX), at $75^{\circ} \mathrm{C}$ for $10 \mathrm{~min}$. RNA yield and purity was determined using the NanoDrop 2000c spectrophotometer (Thermo Scientific).

\section{Reverse Transcription Polymerase Chain Reaction (RT-PCR)}

Reverse transcription of mRNA and subsequent cDNA amplification determined the effect of transposon insertion on transcription for genes of interest. The GoScript ${ }^{\mathrm{TM}}$ Reverse Transcription System was used for cDNA first-strand synthesis according to manufacturer's instructions (Promega Corporation, Madison, WI). RNA (300 ng) and random primers $(0.5 \mu \mathrm{g})$ were denatured at $70^{\circ} \mathrm{C}$ for $5 \mathrm{~min}$ before the addition of $1 \mu \mathrm{l}$ GoScript $^{\mathrm{TM}}$ Reverse Transcriptase, $4 \mu \mathrm{l}$ GoScript ${ }^{\mathrm{TM}} 5 \mathrm{X}$ Reaction Buffer, $\mathrm{MgCl}_{2}, 0.5 \mathrm{mM}$ dNTPs, and nuclease-free water to a final volume of $20 \mu \mathrm{l}$. The primers were annealed at $25^{\circ} \mathrm{C}$ for $5 \mathrm{~min}$ and extended at $42^{\circ} \mathrm{C}$ for $60 \mathrm{~min}$. cDNA was stored at $-20^{\circ} \mathrm{C}$ until amplification.

Amplification was performed on $500 \mathrm{ng}$ cDNA using $10 \mu \mathrm{M}$ forward and reverse gene-specific primers (Table 2). Thermal cycling parameters included initial denaturation at $94^{\circ} \mathrm{C}$ for 5 min followed by 35 cycles of denaturation for $30 \mathrm{sec}\left(94^{\circ} \mathrm{C}\right)$, primer annealing for $30 \mathrm{sec}\left(58^{\circ} \mathrm{C}\right)$, and extension for $2.5 \mathrm{~min}\left(72^{\circ} \mathrm{C}\right)$ with a final elongation at $72^{\circ} \mathrm{C}$ for $7 \mathrm{~min}$. Amplified product was subjected to electrophoresis in a $2 \%$ agarose matrix in $1 \mathrm{X}$ TAE buffer and visualized by ethidium bromide staining.

\section{SOUTHERN HYBRIDIZATION}

Southern hybridization was used to ensure that the phenotypes observed in the pathogenesis mutants were caused by a single insertion of the transposon into the genome. For this study, a probe was designed to detect the kanamycin resistance gene of 
the transposon. The kanamycin gene was amplified from $100 \mathrm{ng}$ of the delivery vector, pUB394, using the PT-KAN primer set $(10 \mu \mathrm{M})$ (Table 2). PCR product was purified using the QIAquick ${ }^{\circledR}$ PCR Purification Kit (Qiagen Inc.) according to manufacturer's instructions and quantified. The Amersham Gene Images AlkPhos Direct Labelling and Detection System (GE Healthcare, Buckinghamshire, UK) was used to label $200 \mathrm{ng}$ Kan product according to manufacturer's instructions. The labeled probe was kept on ice for up to $2 \mathrm{~h}$ before use.

For Southern hybridization, $5 \mu \mathrm{g}$ mutant and primary wild type gDNA were digested overnight with $5 \mathrm{U} \mathrm{Nsi}$ (New England BioLabs Inc.) at $37^{\circ} \mathrm{C}$. As a positive control, 50 ng pUB394 was used. The plasmid was linearized by digesting overnight with $10 \mathrm{U} \mathrm{SacI} \mathrm{(New} \mathrm{England} \mathrm{BioLabs} \mathrm{Inc.)} \mathrm{at} 37^{\circ} \mathrm{C}$. Digests were separated in $0.8 \%$ agarose in $1 \mathrm{X}$ TAE at $6 \mathrm{~V} / \mathrm{cm}$ and visualized with ethidium bromide. The gel was soaked in 0.25 $\mathrm{N} \mathrm{HCl}$ for 15 min with gentle agitation to depurinate the DNA, then rinsed with distilled water. DNA was denatured by soaking the gel in $0.5 \mathrm{M} \mathrm{NaOH}$ and $1.5 \mathrm{M} \mathrm{NaCl}$ for 30 min with gentle agitation. After rinsing with distilled water, the gel was neutralized for 30 $\min$ in $0.5 \mathrm{M}$ Tris-Cl, $\mathrm{pH} 7.0,3 \mathrm{M} \mathrm{NaCl}$ with gentle agitation and equilibrated in $20 \mathrm{X}$ $\mathrm{SSC}(3 \mathrm{M} \mathrm{NaCl}, 0.3 \mathrm{M}$ sodium citrate, $\mathrm{pH} 7.0$ ) for $5 \mathrm{~min}$. A positively-charged nylon membrane (Amersham Pharmacia Biotech) cut slightly larger than the gel was wetted for $1 \mathrm{~min}$ in distilled water and soaked in $20 \mathrm{X} \mathrm{SSC}$ for $5 \mathrm{~min}$. The equilibrated gel and membrane were assembled in a reservoir transfer system and the DNA was transferred overnight using 20X SSC. After transfer, the membrane was washed in 2X SSC for 2 min and the DNA was fixed to the membrane by baking for $2 \mathrm{~h}$ at $80^{\circ} \mathrm{C}$ between two pieces of filter paper in a glass dish. 
Prehybridization (15 min) and hybridization (overnight) of the membrane were performed at $65^{\circ} \mathrm{C}$ using AlkPhos Direct hybridization buffer (GE Healthcare) containing $0.5 \mathrm{M} \mathrm{NaCl}$ and $4 \%$ (w:v) blocking reagent with $200 \mathrm{ng}$ Kan probe according to manufacturer's instructions. Post-hybridization stringency washes were performed at $65^{\circ} \mathrm{C}$ with primary wash buffer $[2 \mathrm{M}$ urea, $0.1 \%$ (w:v) SDS, $50 \mathrm{mM}$ Na phosphate, $\mathrm{pH}$ 7.0, $150 \mathrm{mM} \mathrm{NaCl}, 1 \mathrm{mM} \mathrm{MgCl}_{2}, 0.2 \%$ (w:v) blocking reagent] twice, for $10 \mathrm{~min}$ each, followed by two 5 -min washes at room temperature with secondary wash buffer $(50 \mathrm{mM}$ Tris base, $100 \mathrm{mM} \mathrm{NaCl}, 2 \mathrm{mM} \mathrm{MgCl}_{2}$ ). The membrane was incubated with $40 \mu \mathrm{l} / \mathrm{cm}^{2}$ CDP-Star ${ }^{\mathrm{TM}}$ chemiluminescent detection reagent for $5 \mathrm{~min}$ before wrapping in plastic wrap and exposing to radiography film for $1.5 \mathrm{~h}$. 


\section{CHAPTER III}

\section{RESULTS}

\section{IDENTIFICATION OF HEMOLYSIS MUTANTS}

A previously constructed transposon library consisting of approximately 10,000 primary phase $P$. temperata mutants (Michaels, 2006) was screened for mutants altered in hemolytic activity. The time of hemolysis initiation for each mutant was observed, and mutants displaying markedly different activity from the primary parental wild type were recorded. Primary phase cells displayed annular hemolysis activity between 19 and $24 \mathrm{~h}$ incubation at $28^{\circ} \mathrm{C}$, while secondary phase cells showed no hemolytic activity even with prolonged incubation $(72 \mathrm{~h})$. Since individual mutants with elevated or decreased levels of hemolysis activity were not apparent from this screening protocol, the time required for the initiation of hemolysis was used as a criterion for mutant identification. Initial screening identified mutants in two categories: 756 putative early hemolysis mutants and 1,279 putative defective hemolysis mutants. Putative early mutants had clearing zones visibly larger than the primary parental wild type by $24 \mathrm{~h}$, and putative defective mutants lacked any halo at $48 \mathrm{~h}$. These hemolysis mutants were subsequently confirmed four additional times by spotting $2 \mu \mathrm{l}$ of overnight liquid culture onto blood agar plates. During this confirmation procedure, a third category, delayed hemolysis, was identified from the mutants originally thought to be defective. The delayed mutants were separated based on the initiation of hemolysis between 48 and $72 \mathrm{~h}$, whereas the defective mutants 
had no hemolysis after $72 \mathrm{~h}$. A total of 74 mutants were confirmed and classified as belonging to one of the three different categories of hemolysin mutant: Defective activity, Delayed activity, and Early activity (Table 3). Forty-four mutants were grouped into the defective for hemolysis category and showed no hemolytic activity after $72 \mathrm{~h}$ incubation. Nineteen mutants exhibited a delayed hemolysis phenotype, which was characterized by initiation of hemolysis activity between 48 and $72 \mathrm{~h}$ incubation (approximately $24 \mathrm{~h}$ later than the wild type activity). Eleven mutants had an early hemolysis phenotype, which displayed hemolysis activity after $14-17 \mathrm{~h}$ incubation (approximately $10 \mathrm{~h}$ earlier than the wild type). Confirmed hemolysis mutants were subsequently screened for alterations in other phenotypes. 
Table 3. Hemolysis screening results: Mutant hemolytic categories

\begin{tabular}{lcl} 
Hemolysis & Mutants Identified & Description \\
\hline Defective & 44 & No hemolysis activity after $72 \mathrm{~h}$ \\
Delayed & 19 & Initiation of hemolysis between 48 and $72 \mathrm{~h}$ \\
Early & 11 & Initiation of hemolysis before $17 \mathrm{~h}$ \\
Primary wild type & Positive control & Initiation of hemolysis between 19 and $24 \mathrm{~h}$ \\
Secondary wild type & Negative control & No hemolysis activity after $72 \mathrm{~h}$ \\
\hline
\end{tabular}




\section{Physiological Characterization of the Hemolysis Mutants}

A variety of physiological traits were assessed for the 74 hemolysis mutants and compared to the primary and secondary parental wild types (Table 4). Dye binding and pigmentation were used to assess the phenotypic phase of each mutant to ensure that altered hemolytic activity was not attributed to phase variation. Extracellularly-secreted products including protease, lipase, siderophore, and antimicrobials were evaluated. These are all potential virulence factors and are used to distinguish the primary and secondary phenotypic variants as well. Lastly, swimming and swarming behavior were measured for each mutant to identify altered motility.

The majority of the hemolysis mutants had all or most of their phenotypes resemble those of the primary parental wild type. The most physiological variation was observed in the defective hemolysis group; 19 of the 44 mutants had strictly primary characteristics, while 17 mutants displayed a mix of predominantly primary traits with some secondary characteristics. Within this group were 5 mutants defective for protease, one mutant defective for lipase, one mutant defective in both lipase and protease, 3 mutants defective in swarming motility, 3 mutants defective in swimming motility, one mutant defective in both swimming and swarming, two lacking colony pigmentation, and one defective in dye binding, lipase, antibiotic production, swimming, and swarming. Only 8 defective hemolysis mutants displayed primarily secondary characteristics; however, none of these mutants had phenotypes that were entirely secondary. These data indicate that all mutants were primary variants, but that the transposon insertion often disrupted phenotypes other than hemolysis. All 19 delayed hemolysis mutants displayed mostly primary phenotypes, only resembling the secondary in, at most, two 
characteristics for any given mutant ( 5 mutants were strictly primary). Interestingly, 6 of the delayed hemolysis mutants were unable to grow on the CAS siderophore media. There was one mutant defective for swarming, two defective for swimming, one defective for both swimming and swarming, one defective for antibiotic production and swimming, one with reduced siderophore activity, one that bound calcofluor, and one that bound calcofluor and could not swarm. Lastly, all early hemolysis mutants, with the exception of $86 \mathrm{C} 7$, were physiologically identical to the primary parental wild type.

Since hemolysis mutants were identified based on early or delayed activity, the effects of growth rate needed to be considered. Growth assays were performed on all 74 hemolysis mutants (Data not shown). The majority of mutants exhibited growth rates similar to the primary phase parental wild type. For the early hemolysis mutants, 9 out of the 11 mutants also had growth rates similar to the parental wild type; however, two early hemolysis mutants (86 C7 and $82 \mathrm{H12}$ ) actually displayed growth rates that were slower than that of the parental wild type (Figure 5). These results indicate that the altered hemolysis activity observed for these mutants was not the consequence of altered growth rates. 


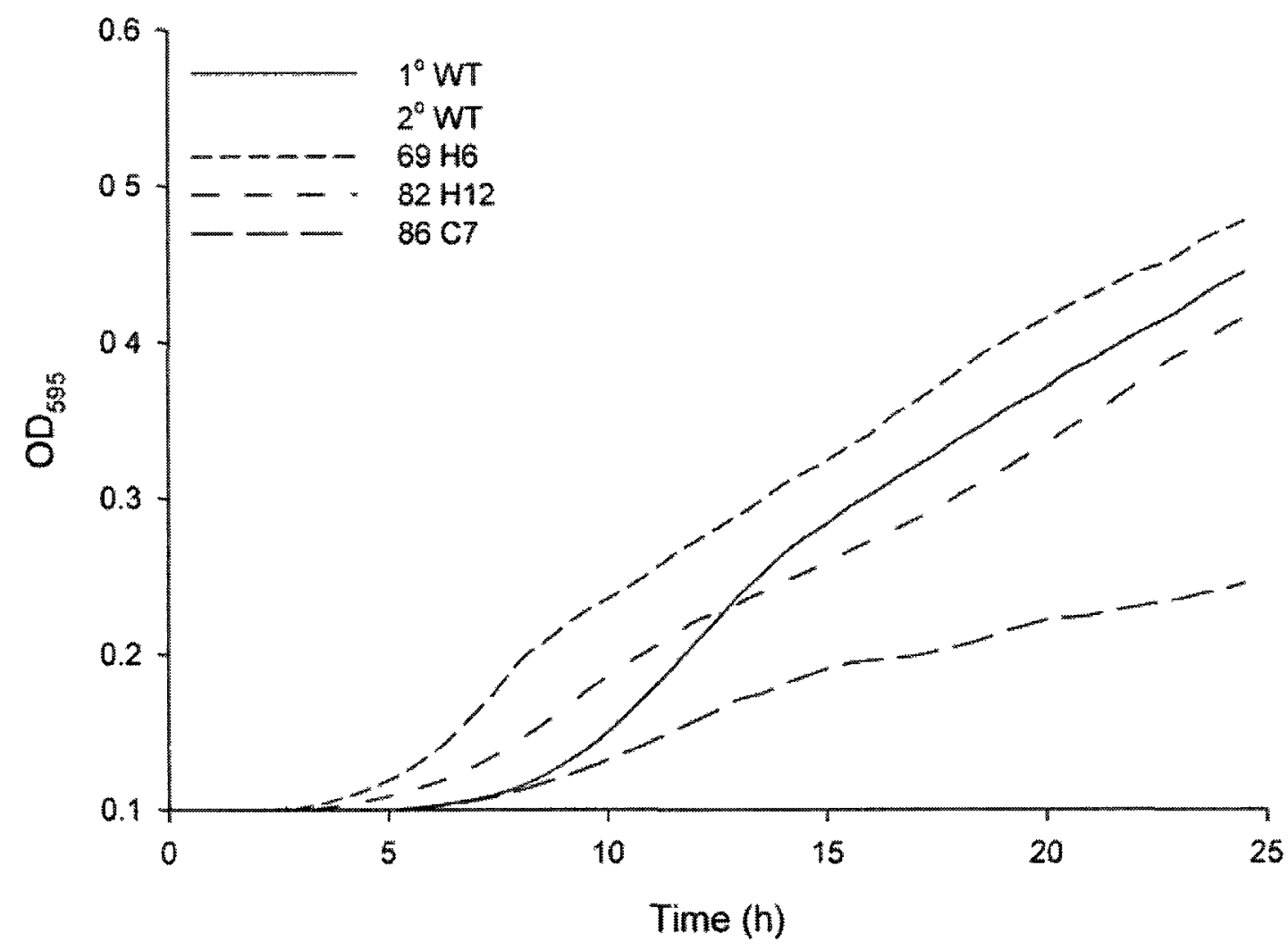

Figure 5. Selected hemolysis mutants were assessed for growth defects via a 24-h growth assay. Representative data points for three mutants are shown above. $82 \mathrm{H} 12$ and $86 \mathrm{C} 7$ had slightly decreased growth rates. $69 \mathrm{H} 6$ shows a growth rate comparable to the wild type. The other 71 hemolysis mutants displayed similar trends. 
Table 4. Physiological properties of $P$. temperata mutants altered in hemolytic activity and their parental wild types

\begin{tabular}{|c|c|c|c|c|c|c|c|c|c|c|c|}
\hline Strain & Pigment & EMB & MAC & NBTA & Calc & Lipase & Protease & Antibiotic & CAS & Swim & Swarm \\
\hline \multicolumn{12}{|l|}{ Parental: } \\
\hline $1^{\circ} \mathrm{WT}$ & Dark & + & + & + & - & + & + & 4 & + & 45 & 85 \\
\hline $2^{\circ} \mathrm{WT}$ & Light & - & - & - & + & - & + & 0 & + & 10 & 13 \\
\hline \multicolumn{12}{|l|}{ Defective: } \\
\hline $10 \mathrm{~A} C 11$ & Light & - & - & - & + & - & + & 1 & + & 10 & 10 \\
\hline 10A H12 & Light & - & - & - & + & - & $+/-$ & 1 & + & 9 & 9 \\
\hline $11 \mathrm{~A} D 12$ & Dark & + & + & + & - & + & + & 4 & + & 50 & 54 \\
\hline $12 \mathrm{~A} \mathrm{G} 7$ & Light & - & $+1-$ & - & + & - & + & 2 & + & 11 & 10 \\
\hline $2 \mathrm{HI} 2$ & Light & - & $+/-$ & $+/-$ & + & - & + & 1 & + & 16 & 11 \\
\hline $5 \mathrm{~A} 12$ & Dark & + & + & + & - & + & + & 3 & + & 34 & 25 \\
\hline $22 \mathrm{~A} 2$ & Dark & + & + & + & - & + & - & 3 & + & 35 & 85 \\
\hline $24 \mathrm{G} 12$ & Dark & + & + & + & - & + & + & 4 & + & 41 & 58 \\
\hline $36 \mathrm{Cl} 10$ & Dark & + & + & + & - & + & + & 3 & + & 28 & 45 \\
\hline $37 \mathrm{Cl}$ & Dark & + & + & + & - & + & + & 4 & + & 27 & 30 \\
\hline $38 \mathrm{D} 10$ & Dark & + & + & + & - & + & + & 3 & + & 29 & 55 \\
\hline $38 \mathrm{E} 11$ & Dark & + & + & + & - & + & - & 3 & + & 40 & 85 \\
\hline $40 \mathrm{D} 10$ & Dark & + & + & + & - & + & + & 4 & + & 36 & 55 \\
\hline $40 \mathrm{E} 7$ & Dark & + & + & + & - & + & + & 5 & + & 34 & 56 \\
\hline $41 \mathrm{~B} 3$ & Light & + & + & + & - & + & + & 4 & + & 36 & 50 \\
\hline $46 \mathrm{G} 6$ & Dark & + & + & + & - & + & + & 4 & + & 12 & 12 \\
\hline $47 \mathrm{H} 6$ & Dark & + & + & + & - & + & + & 3 & + & 26 & 32 \\
\hline $50 \mathrm{C} 5$ & Dark & + & + & + & - & + & + & 3 & + & 28 & 29 \\
\hline $51 \mathrm{~F} 9$ & Dark & + & + & + & - & + & + & 3 & + & 26 & 54 \\
\hline $53 \mathrm{H} 3$ & Dark & - & - & + & + & NG & + & 2 & + & 4 & 9 \\
\hline $56 \mathrm{H} 7$ & Dark & + & + & + & - & - & + & 3 & + & 31 & 78 \\
\hline $60 \mathrm{~A} 2$ & Dark & + & + & + & - & + & - & 4 & + & 40 & 85 \\
\hline
\end{tabular}









\begin{tabular}{|c|c|c|c|c|c|c|c|c|c|c|c|}
\hline $\begin{array}{c}\text { Table } 4 \text { (cont.) } \\
\text { Strain } \\
\end{array}$ & Pigment & EMB & MAC & NBTA & Calc & Lipase & Protease & Antibiotic & $\mathrm{CAS}$ & Swim & Swarm \\
\hline \multicolumn{12}{|c|}{ Delayed: } \\
\hline $26 \mathrm{C} 4$ & Dark & + & + & + & - & + & + & 5 & NG & 42 & 85 \\
\hline $26 \mathrm{E} 6$ & Dark & + & + & + & - & + & + & 4 & + & 3 & 8 \\
\hline $30 \mathrm{C} 6$ & Dark & + & + & + & - & + & + & 5 & NG & 45 & 85 \\
\hline $30 \mathrm{~F} 2$ & Dark & + & + & + & + & + & + & 5 & + & 23 & 9 \\
\hline $32 \mathrm{C} 5$ & Dark & + & + & + & - & + & + & 5 & NG & 40 & 85 \\
\hline $32 \mathrm{E} 4$ & Dark & + & + & + & - & + & + & 4 & $\mathrm{NG}$ & 45 & 80 \\
\hline 34 E2 & Dark & + & + & + & - & + & + & 5 & NG & 45 & 85 \\
\hline 36 D6 & Dark & + & + & + & - & + & + & 4 & + & 35 & 69 \\
\hline $37 \mathrm{C} 5$ & Dark & + & + & + & - & + & + & 5 & + & 30 & 9 \\
\hline 38 A 10 & Dark & + & + & + & - & + & + & 4 & + & 30 & 36 \\
\hline $40 \mathrm{E} 6$ & Dark & + & + & + & + & + & + & 6 & + & 36 & 48 \\
\hline 41 D5 & Dark & + & $+/-$ & + & - & + & + & 5 & NG & 38 & 85 \\
\hline $59 \mathrm{G} 4$ & Dark & + & + & + & - & + & + & 0 & + & 22 & 55 \\
\hline $62 \mathrm{~A} 7$ & Dark & + & + & + & - & + & + & 5 & + & 24 & 53 \\
\hline 65 D5 & Dark & + & + & + & - & + & + & 5 & + & 22 & 85 \\
\hline $67 \mathrm{H1}$ & Dark & + & $+/-$ & + & - & + & + & 5 & $+/-$ & 35 & 85 \\
\hline $69 \mathrm{H} 6$ & Dark & + & + & + & - & + & + & 6 & + & 31 & 85 \\
\hline 72 F9 & Dark & + & + & + & - & + & + & 5 & + & 42 & 85 \\
\hline $86 \mathrm{G} 2$ & Dark & + & + & + & - & + & + & 4 & + & 31 & 70 \\
\hline
\end{tabular}


Table 4 (cont.)

\begin{tabular}{|c|c|c|c|c|c|c|c|c|c|c|c|}
\hline Strain & Pigment & EMB & MAC & NBTA & Calc & Lipase & Protease & Antibiotic & CAS & Swim & Swarm \\
\hline \multicolumn{12}{|l|}{ Early: } \\
\hline 9A F6 & Dark & + & + & + & - & + & + & 4 & + & 40 & 85 \\
\hline $24 \mathrm{~A} 4$ & Dark & + & + & + & - & + & + & 4 & + & 66 & 85 \\
\hline $27 \mathrm{G} 12$ & Dark & + & + & + & - & + & + & 4 & + & 43 & 85 \\
\hline 35 B9 & Dark & + & + & + & - & + & + & 4 & + & 55 & 85 \\
\hline $36 \mathrm{D} 3$ & Dark & + & + & + & - & + & + & 4 & + & 53 & 85 \\
\hline $38 \mathrm{C} 10$ & Dark & + & + & + & - & + & + & 4 & + & 35 & 85 \\
\hline $38 \mathrm{G} 3$ & Dark & + & + & + & - & + & + & 4 & + & 61 & 85 \\
\hline $59 \mathrm{G} 6$ & Dark & + & + & + & - & + & + & 4 & + & 69 & 85 \\
\hline $61 \mathrm{E} 8$ & Dark & + & + & + & - & + & + & 4 & + & 40 & 85 \\
\hline $82 \mathrm{H} 12$ & Dark & + & + & + & - & + & + & 5 & + & 47 & 85 \\
\hline $86 \mathrm{C} 7$ & Dark & - & - & - & + & - & + & 2 & $+/-$ & 43 & 85 \\
\hline
\end{tabular}

$\$$ Pigment: Determined by growth on LB agar. Dark pigmented colonies appear orange or yellow in color while light colonies appear white or off-white. EMB (Eosin Methylene Blue): Positive (+) dye absorption was indicated by shiny metallic green colonies, while negative (-) colonies were pink or purple. MAC (MacConkey): Positive colonies were red colored while negative colonies were pale pink or orange $\left(+/\right.$ - denotes light red colonies less pigmented than the $1^{\circ}$ but more than the $\left.2^{\circ}\right)$. NBTA (Nutrient Bromothymol Blue Agar): Positive colonies were dark green while negative colonies were light green or pink ( $+/$ - denotes green colonies of medium shade). Calc (Calcofluor): Positive binding of calcofluor fluoresced under UV light while negative did not fluoresce. Lipase and Protease: Positive reactions were indicated by a halo around the colony ( $\geq 1 \mathrm{~mm}$ for lipase, $\geq 2 \mathrm{~mm}$ for protease), while negative reactions lacked a halo ( $+/$ - on protease indicates a halo of $\leq 2 \mathrm{~mm}$ ). Antibiotic: The radius of clearing surrounding each colony was recorded in mm. CAS (Chrome Azurol S): Positive siderophore production was noted by an orange halo $(\geq 2 \mathrm{~mm})$ surrounding the colony, while negative production lacked such a halo ( $+/$ - indicates a halo $\leq 2 \mathrm{~mm})$. Swim and Swarm: The diameters of swim and swarm rings were recorded in $\mathrm{mm}$ at $48 \mathrm{~h}$ incubation. NG (No growth): Repeated culturing attempts yielded no growth of some mutants on certain media. All data were recorded at $48 \mathrm{~h}$ incubation at $28^{\circ} \mathrm{C}$. 


\section{IDENTIFICATION OF PATHOGENESIS MUtaNTS}

We were interested in the role that hemolysis activity plays in insect pathogenesis and tested this property by the use of an in vitro insect pathogenesis assay. Standardized numbers of cells for mutants and parental wild type were injected directly into the hemocoel of Galleria mellonella larvae and insect mortality was monitored over time as described in the Methods. Figure 6 shows the representative results for the parental wild types and select mutants. Virulence was determined by calculating the time required to kill $50 \%$ of the larval population infected $\left(\mathrm{LT}_{50}\right)$ and the time required to kill the entire population $\left(\mathrm{LT}_{100}\right)$. Although the exact times varied by data set, the primary phase parental wild type killed half of the infected larvae on average by $47 \mathrm{~h}\left(\mathrm{LT}_{50}\right)$ and the entire larval population on average by $55 \mathrm{~h}\left(\mathrm{LT}_{100}\right)$. Secondary phase parental wild type cells were more virulent and had an average $\mathrm{LT}_{50}$ and $\mathrm{LT}_{100}$ of $44 \mathrm{~h}$ and $50 \mathrm{~h}$, respectively. All of the hemolysis mutants killed the insects; however, none of the mutants killed faster than the parental wild type. For the mutants defective in hemolytic activity, 15 out of the 44 mutants were also defective in pathogenesis during initial screening (Table 5). These mutants showed a delayed pathogenesis response that was 10$20 \mathrm{~h}$ later than the primary phase parental wild type (Figure 6). For the delayed hemolysis group, 10 out of the 19 mutants also exhibited a delayed response for pathogenesis. All of the 11 early hemolysis exhibited a pathogenesis response similar to the parental wild type. These results indicate that hemolysis activity is not required for insect killing, but may play a role in the pathogenesis process. The 25 mutants altered in both hemolysis and insect pathogenesis were selected for further study. 


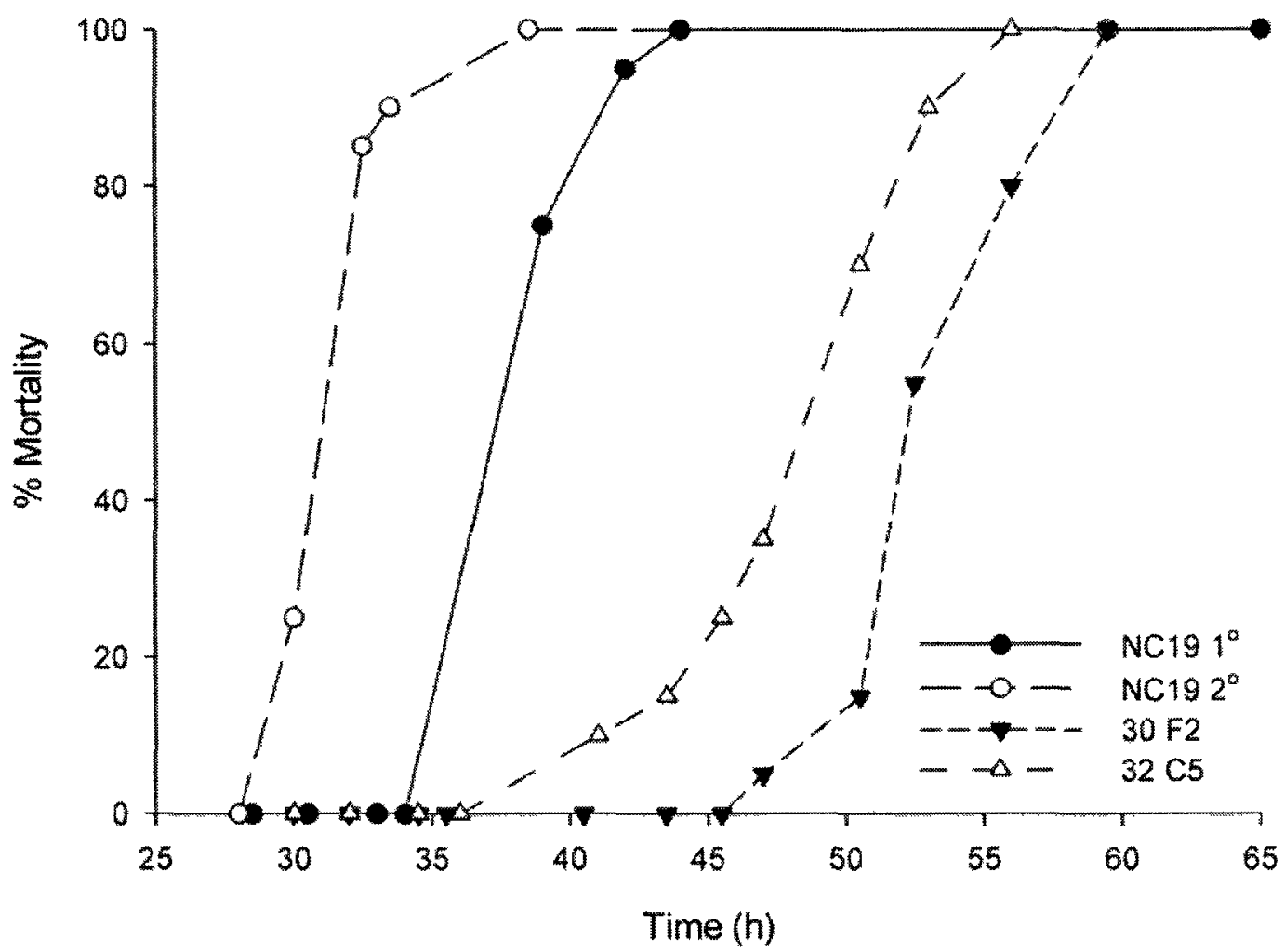

FiguRE 6. The in vitro insect pathogenesis assay identified 25 hemolytic mutants that exhibited a delayed response in pathogenesis. The delayed pathogenesis response was characterized by an increase in the $\mathrm{LT}_{50}$ and $\mathrm{LT}_{100}$ by $\geq 10 \mathrm{~h}$ compared to primary parental wild type. Representative data points for two mutants are shown above. The other 20 putative virulence mutants showed similar trends (Table 5). 
Table 5. Hemolysis mutants altered in insect pathogenesis as identified by preliminary screening. An in vitro insect pathogenesis assay was used to determine $\mathrm{LT}_{50}$ and $\mathrm{LT}_{100}$ as described in the Materials and Methods. For these assays, 100 cells were inoculated into each of 20 larvae.

\begin{tabular}{|c|c|c|c|c|}
\hline Mutant & Hemolysis & $\mathrm{LT}_{50}$ & $\mathrm{LT}_{100}$ & $\begin{array}{c}\text { MOI } \\
\text { Confirmed }\end{array}$ \\
\hline $1^{\circ} \mathrm{WT}$ & + & 47 & 55 & - \\
\hline $2^{\circ} \mathrm{WT}$ & - & 44 & 50 & - \\
\hline $10 \mathrm{~A} \mathrm{C} 11$ & Defective & 59 & 69 & YES \\
\hline 10A H12 & Defective & 59 & 68 & YES \\
\hline $46 \mathrm{G} 6$ & Defective & 60 & 69 & YES \\
\hline $50 \mathrm{C5}$ & Defective & 60 & 66 & YES \\
\hline $53 \mathrm{H} 3$ & Defective & $>68$ & $>68$ & YES \\
\hline $79 \mathrm{~B} 5$ & Defective & 71.5 & 91.5 & YES \\
\hline $30 \mathrm{C} 6$ & Delayed & 57 & 65 & YES \\
\hline $30 \mathrm{~F} 2$ & Delayed & 57 & 65 & YES \\
\hline $32 \mathrm{C} 5$ & Delayed & 56 & 65 & YES \\
\hline $34 \mathrm{E} 2$ & Delayed & 53 & 65 & YES \\
\hline $12 \mathrm{~A} \mathrm{G} 7$ & Defective & 55.5 & 64.5 & - \\
\hline $2 \mathrm{H} 12$ & Defective & 59 & $>59$ & - \\
\hline $24 \mathrm{G} 12$ & Defective & 58.5 & 71.7 & - \\
\hline $51 \mathrm{~F} 9$ & Defective & $>57$ & $>65$ & - \\
\hline $56 \mathrm{H} 7$ & Defective & 52 & 68 & - \\
\hline $60 \mathrm{~A} 2$ & Defective & $>52.8$ & $>52.8$ & - \\
\hline $84 \mathrm{E} 1$ & Defective & 56 & $>56$ & - \\
\hline $89 \mathrm{~F} 5$ & Defective & 56 & $>56$ & - \\
\hline $90 \mathrm{E} 2$ & Defective & 55.5 & $>56$ & - \\
\hline $26 \mathrm{C} 4$ & Delayed & 56 & 77.5 & - \\
\hline $26 \mathrm{E} 6$ & Delayed & $>58$ & $>58$ & - \\
\hline $32 \mathrm{E} 4$ & Delayed & 57.5 & 67.5 & - \\
\hline 36 D6 & Delayed & 62.5 & 71.5 & - \\
\hline $41 \mathrm{D} 5$ & Delayed & $>61$ & $>61$ & - \\
\hline $59 \mathrm{G} 4$ & Delayed & 53 & 64 & - \\
\hline
\end{tabular}

Mutant $\mathrm{LT}_{50}$ and $\mathrm{LT}_{100}$ values were standardized to the average $\mathrm{LT}_{50}$ and $\mathrm{LT}_{100}$ of the primary parental wild type. Initial pathogenesis testing identified 25 putative virulence mutants. Multiplicity of infection (MOI) assays performed with four different infectious doses confirmed 10 mutants that remained delayed in pathogenesis by 10 or more $\mathrm{h}$ after injection with each dose. 


\section{CONFIRMation of Pathogenesis MUTANTS}

The effect of cell dosage on insect pathogenesis was determined for the 25 identified hemolysis mutants. Figure 7 shows the results of representative mutants compared to the parental wild type. Multiplicity of infection (MOI) was tested by the use of variable infectious doses ranging from 10 to 10,000 cells (four doses for each mutant). MOI assays showed that 10 out of the 25 hemolysis mutants that displayed reduced virulence during the initial screen maintained their delayed virulence. These confirmed pathogenesis mutants were $10 \mathrm{~A} \mathrm{C} 11,10 \mathrm{~A} \mathrm{H} 12,30 \mathrm{C} 6,30 \mathrm{~F} 2,32 \mathrm{C} 5,34 \mathrm{E} 2,46 \mathrm{G} 6,50$ $\mathrm{C} 5,53 \mathrm{H} 3$, and $79 \mathrm{~B} 5$. Only those mutants that were consistently delayed by $10 \mathrm{~h}$ at each of the four dosages were counted; mutants that were delayed at some of the doses but not all were not considered true pathogenesis mutants. Typically, these mutants would exhibit delayed pathogenesis at lower dosages, but as the cellular density increased, the mutants had close to wild type pathogenesis, likely due to the accumulation of toxins produced. Of the 10 confirmed pathogenesis mutants, seven were defective for hemolysis and four had delayed hemolysis (Table 6). 
A)



C)
B)

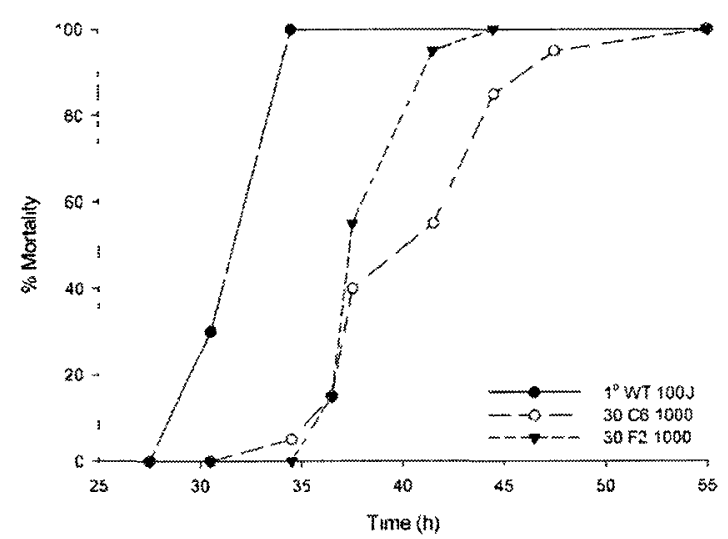

D)

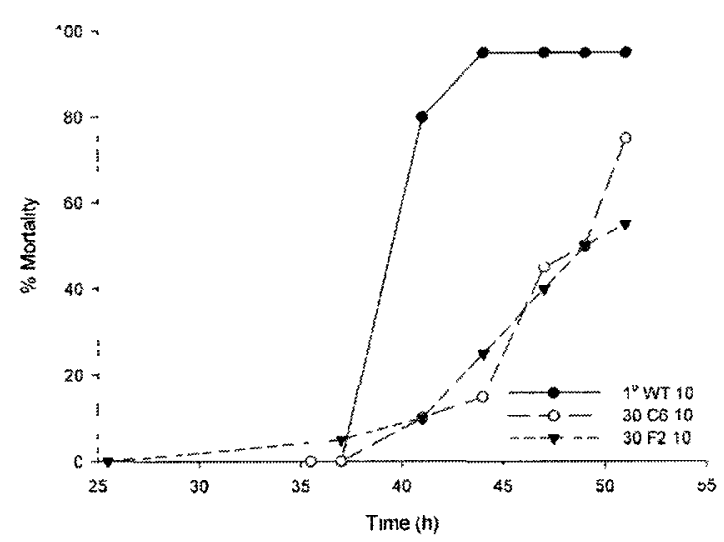

FiguRE 7. The effect of cell dosage [multiplicity of infection (MOI)] on insect pathogenesis by the hemolytic mutants. Four MOI values of Photorhabdus were injected into $20 \mathrm{G}$. mellonella larvae A) 10,000 cells, B) 1,000 cells, C) 100 cells, and D) 10 cells. Representative data points for two mutants are shown above. The other 8 confirmed virulence mutants showed similar trends. 


\section{Further Phenoty pic Characterization of \\ CONFIRMED PATHOGENESIS MUTANTS}

The ten confirmed pathogenesis mutants were selected for a more quantitative look at physiological characteristics. These mutants were again assayed as previously described (Table 4) with the inclusion of DNase activity. Clearing zones and halos for lipase, protease, antimicrobial activity, siderophore production, and DNase activity were measured in $\mathrm{mm}$ (radius), and the diameters of swim and swarm rings were quantified as well (mm) (Table 6). Interestingly, all of the ten mutants were altered in at least one additional phenotype; no mutants were altered only in hemolysis and pathogenesis. A closer look at these ten mutants reveals that two of the defective hemolysis/delayed pathogenesis mutants, $10 \mathrm{~A} \mathrm{C11}$ and 10A H12, appear identical and may have sibling mutations. As mentioned previously, no mutants entirely lack primary characteristics. Interestingly, $30 \mathrm{C} 6,32 \mathrm{C} 5$, and $34 \mathrm{E} 2$, which are delayed hemolysis/delayed pathogenesis, all have increased production of protease and antibiotics compared to the primary parental wild type, and are unable to grow on the siderophore medium, again indicating possible mutations in the same gene. 46 G6 is impaired in both swimming and swarming motility, and mildly defective in protease, DNase, and siderophore production, however retains wild type levels of lipase and antibiotic production. $53 \mathrm{H} 3$ is nonmotile, has decreased secretion of protease, antibiotics, and siderophore, and does not grow on lipase medium. 79 B5 has decreased protease, siderophore, and DNase activity, and is defective for swarming. 50 C5 has decreased secretion of all extracellular products, except for DNase. 30 F2 has increased antibiotic activity, decreased siderophore activity, and is unable to swarm. The wide variations in phenotypes observed even within this small group of mutants demonstrate the diversity of genes affecting virulence. 
Table 6. Quantitative physiological analysis of 10 mutants altered in hemolytic activity and delayed in virulence

\begin{tabular}{|c|c|c|c|c|c|c|c|c|c|c|c|}
\hline Strain & Hemolysis & Pigment & Dye Binding & Calc & Lipase & Protease & Antibiotic & CAS & DNase & Swim & Swarm \\
\hline $1^{\circ} \mathrm{WT}$ & + & Dark & + & - & 2 & 3 & 4 & 5 & 2 & 52 & 85 \\
\hline $2^{\circ} \mathrm{WT}$ & - & Light & - & + & 0 & 2 & 0 & 4 & 1 & 10 & 13 \\
\hline 10A C11 & Defective & Light & - & + & 0 & 1 & 1 & 4 & 1 & 10 & 10 \\
\hline 10A H12 & Defective & Light & - & + & 0 & 1 & 1 & 4 & 1 & 9 & 9 \\
\hline $30 \mathrm{C} 6$ & Delayed & Dark & + & - & 2 & 4 & 5 & $\mathrm{NG}$ & 2 & 45 & 85 \\
\hline $30 \mathrm{~F} 2$ & Delayed & Dark & + & + & 2 & 3 & 5 & 4 & 2 & 23 & 9 \\
\hline $32 \mathrm{C} 5$ & Delayed & Dark & + & - & 2 & 4 & 5 & $\mathrm{NG}$ & 2 & 40 & 85 \\
\hline $34 \mathrm{E} 2$ & Delayed & Dark & + & - & 2 & 4 & 5 & NG & 2 & 45 & 85 \\
\hline $46 \mathrm{G} 6$ & Defective & Dark & + & - & 2 & 2 & 4 & 4 & 1 & 12 & 12 \\
\hline $50 \mathrm{C} 5$ & Defective & Dark & + & - & 1 & 2 & 3 & 3 & 2 & 28 & 29 \\
\hline $53 \mathrm{H} 3$ & Defective & Dark & $+/-$ & + & NG & 1 & 2 & 2 & 2 & 4 & 9 \\
\hline $79 \mathrm{~B} 5$ & Defective & Light & $+/-$ & - & 2 & 2 & 4 & 2 & 1 & 38 & 10 \\
\hline
\end{tabular}

Hemolysis activity determined as previously described (Table 3). Pigment: Determined by growth on LB agar. Dark pigmented colonies appear orange or yellow in color while light colonies appear white or off-white. Dye binding determined by absorbance of dyes on EMB, MAC, and NBTA as previously described (Table 4). Calc (Calcofluor): Positive binding of calcofluor fluoresced under UV light while negative did not fluoresce. Extracellular secretion of lipase, protease, antibiotics, and siderophore quantified by measuring the radius of zones/halos in mm. DNase: Production of DNase was indicated by a halo around the colony. The radius of clearing surrounding each colony was recorded in $\mathrm{mm}$. Swim and swarm: The diameters of swim and swarm rings were recorded in $\mathrm{mm}$ at $48 \mathrm{~h}$ incubation. NG (No growth): Repeated culturing attempts yielded no growth of some mutants on certain media. 


\section{Quantification of Pathogenesis Mutant Hemolytic ACTIVITy}

A liquid hemolysis assay was used to quantify the amount of blood lysing activity in the 10 pathogenesis mutants. Samples were measured over a four hour time period and hemolytic units were calculated and plotted over time. The hemolytic activity of each mutant was compared to the primary parental wild type. Figure 8a shows two representative mutants compared to the parental wild types. 79 B5 exhibited a delay in the initiation of hemolysis, but once lysing began, the activity followed the same trend as the primary. The collective data showed that, although all of the mutants were in some way inhibited for hemolysis on blood agar plates, they retained blood lysing activity in the liquid assay (Table 7). A few mutants actually showed hemolytic activity earlier than the primary. Hemolytic activity was also present in the secondary wild type, which is negative for hemolysis on blood agar. The secondary variant had hemolytic activity equal to that of the primary; however, the level of hemolysis was decreased in some mutants.

Each culture was tested for hemolysis using a diluted culture sample, a PBSwashed cell sample, and a filter-sterilized supernatant sample. Figure $8 \mathrm{~b}$ compares the three sample types for the primary parental wild type. For each culture, wild type and mutant alike, the highest hemolytic activity was observed in the diluted culture sample (Data not shown). Hemolysis was detected in the washed cell samples, but was greatly decreased. None of the samples showed any hemolysis in the supernatant samples. These data indicate that the presence of bacterial cells is required for hemolysis, but the activity is enhanced by the presence of culture medium as well. 



FIGURE 8. Hemolytic units vs. time in a liquid hemolysis assay. A) Representative data points for two mutants are shown above. The other 8 mutants displayed similar trends. B) Hemolytic activity was strongest in diluted culture and substantially decreased in PBSwashed cell samples. Filter-sterilized supernatant lacked hemolytic activity. This was true for both primary and secondary parental wild types, as well as the 10 pathogenesis mutants. 
Table 7. Hemolytic units of parental wild types and pathogenesis mutants over time in a liquid hemolysis assay using diluted culture

\begin{tabular}{ccccc} 
Strain & Hour 1 & Hour 2 & Hour 3 & Hour 4 \\
\hline $1^{\circ} \mathrm{WT}$ & 0.00 & 0.00 & 0.73 & 1.98 \\
$2^{\circ} \mathrm{WT}$ & 0.00 & 0.00 & 0.59 & 2.51 \\
$10 \mathrm{~A} \mathrm{C11}$ & 0.00 & 0.13 & 0.55 & 1.65 \\
$10 \mathrm{~A} \mathrm{H12}$ & 0.00 & 0.00 & 0.64 & 2.00 \\
$30 \mathrm{C6}$ & 0.00 & 0.78 & 0.70 & 1.34 \\
$30 \mathrm{~F} 2$ & 0.00 & 0.00 & 1.41 & 1.98 \\
$32 \mathrm{C} 5$ & 0.00 & 0.00 & 1.21 & 1.68 \\
$34 \mathrm{E} 2$ & 0.00 & 0.35 & 1.73 & 2.67 \\
$46 \mathrm{G} 6$ & 0.00 & 0.00 & 0.56 & 1.90 \\
$50 \mathrm{C5}$ & 0.00 & 0.00 & 0.70 & 1.34 \\
$53 \mathrm{H3}$ & 0.00 & 0.00 & 0.59 & 1.44 \\
$79 \mathrm{~B} 5$ & 0.00 & 0.00 & 0.12 & 0.94 \\
\hline
\end{tabular}

$50 \mathrm{C} 5$ and $53 \mathrm{H} 3$ were tested separately and have been standardized to the primary parental wild type in this data set. All mutants and wild types showed an increase in hemolysis over time. 


\section{Molecular Characterization of VIRULence Mutants}

Several of the hemolysis mutants were analyzed at the genetic level to identify the site of transposon insertion.

\section{SOUTHERN HYBRIDIZATION TO CONFIRM SINGLE INSERTIONS}

Southern hybridization was performed to verify that there was only one transposon insertion in the genomes of the ten pathogenesis mutants. The transposon is designed to insert only once into the genome; however, multiple insertions can occur, which could possibly explain the altered effects on both hemolysis and virulence in these mutants. A fluorescently-labeled probe designed to bind to the kanamycin gene was used to identify the number of insertions in each mutant. Multiple insertions would be visible as multiple bands on the blot; however, only one band was seen for each sample. Results from Southern hybridization revealed that all ten of the pathogenesis mutants contained a single transposon insertion in the genome (Figure 9). 


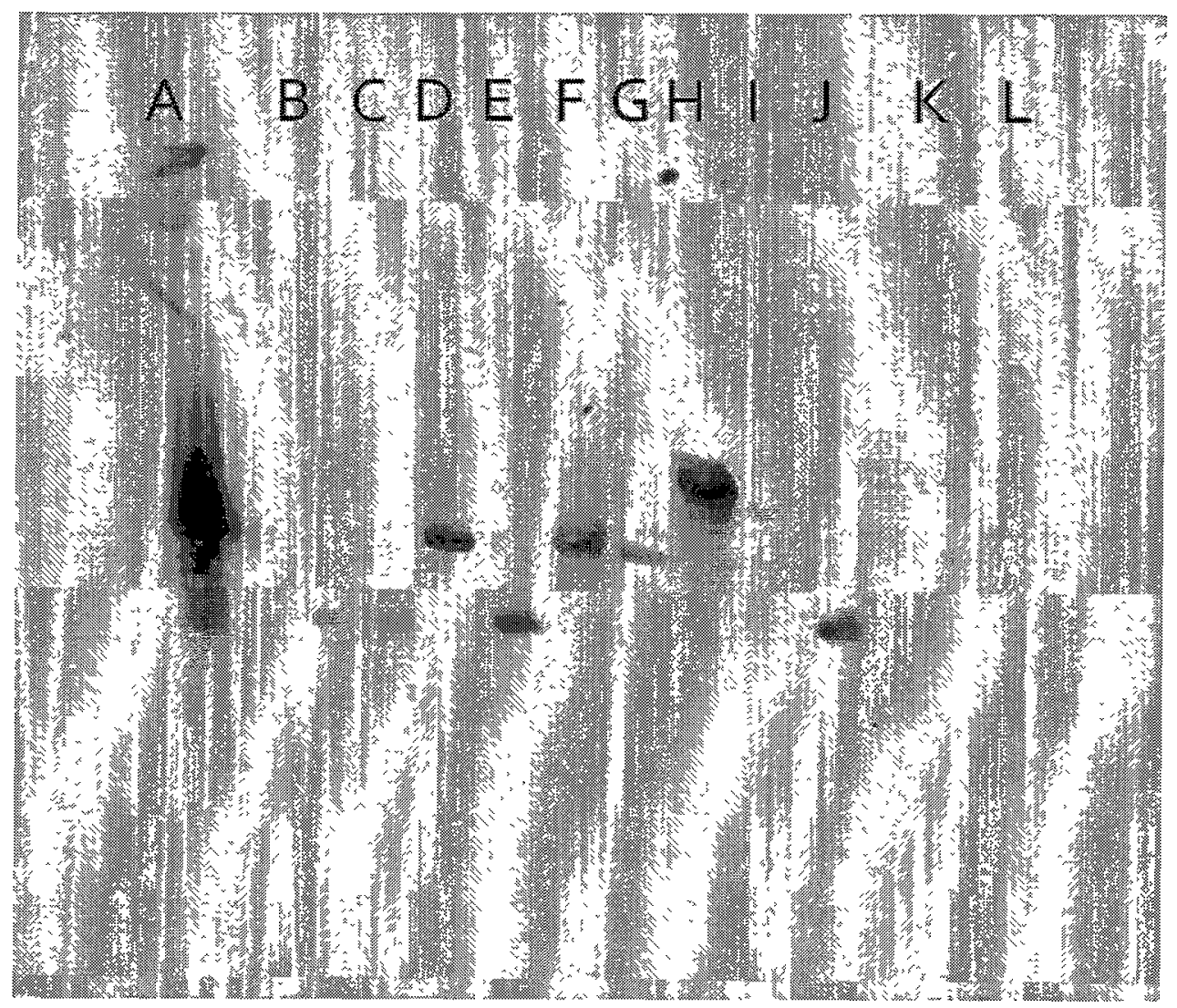

FIGURE 9. Southern blotting confirmed single transposon insertions for the pathogenesis mutants. One band was detected by the fluorescently-labeled Kan probe for each sample. A: pUB394 positive control, B: 10A C11, C: 10A H12, D: 30 C6, E: 30 F2, F: 32 C5, G: $34 \mathrm{E} 2, \mathrm{H}: 46 \mathrm{G} 6$, I: $50 \mathrm{C5}$, J: $53 \mathrm{H3}$, K: 79 B5, L: primary wild type negative control. 


\section{IDENTIFICATION OF TRANSPOSON INSERTION SITES}

Rescue cloning was used to identify the specific site of the transposon insertion.

The transposon and flanking gene region was recovered via rescue cloning and plasmid sequencing. Sequencing of the rescued plasmid determined the genes disrupted by the transposon (Tn5). The sequenced plasmids were compared to the $P$. temperata $\mathrm{NC} 19$ genome, providing a good database for site identification. The availability of the $P$. luminescens subsp. laumondii TT01 and P. asymbiotica subsp. asymbiotica ATCC 43949 genomes also provided a good baseline for comparison. The insert site for 16 mutants displaying different hemolytic and pathogenic phenotypes were identified (Table 8). Interestingly, although the $P$. temperata genome contains at least 24 hemolysis genes, none of the 16 characterized mutants had the transposon inserted into genes directly involved in hemolysis. Instead, the observed phenotypic defects were due to disruptions in genes mainly involved in outer membrane proteins, export systems, and RNA degradation. A few mutants had disruptions in other types of genetic elements, including a transposase and a phage repressor protein. Of particular interest, however, were those mutants confirmed to have alterations in both hemolysis and virulence.

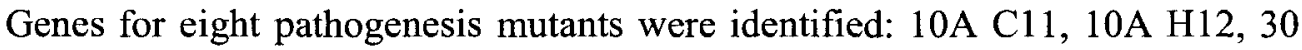
$\mathrm{C} 6,30 \mathrm{~F} 2,46 \mathrm{G} 6,50 \mathrm{C} 5,53 \mathrm{H} 3$, and $79 \mathrm{~B} 5$. Mutants 10A C11, 10A H12, and $79 \mathrm{~B} 5$ had disruptions in genes involved in RNA degradation. 10A C11 and 10A H12 mapped to a gene encoding Exoribonuclease II, a gene previously identified in a mutant altered in motility and pathogenesis (Rowedder, 2009). 79 B5 mapped to a gene encoding an adenosine (5')-pentaphospho-(5")-adenosine pyrophosphohydrolase, which belongs to the nudix superfamily of RNases. Additional pathogenesis mutants identified several hypothetical proteins ( $30 \mathrm{~F} 2$ and $50 \mathrm{C} 5$ ), an LPS heptosyltransferase I (53 H3), a 
carbamoyl-phosphate synthase large subunit (30 C6), and a transposase (46 G6). 46 G6 mapped to a transposase with seven identical paralogs in the genome. Additional sequencing with forward primer M13F determined that the transposon had been inserted in pte 4664, the transposase located on contig 9, which is adjacent to a secreted protein Hcp (hemolysin co-regulated protein), part of the Type VI secretion system. 
Table 8. Transposon insertion sites for mutants of interest

\begin{tabular}{|c|c|c|c|c|c|}
\hline Mutant & $\begin{array}{l}\text { Identity } \\
(\%) \text { E value }\end{array}$ & Gene & $\begin{array}{l}\text { Plu or Pau } \\
\text { homologue }\end{array}$ & Insert Site & $\begin{array}{l}\text { Predicted/Postulated } \\
\text { Gene function }\end{array}$ \\
\hline \multicolumn{6}{|l|}{$\begin{array}{l}\text { Defective hemolysis/ } \\
\text { WT virulence }\end{array}$} \\
\hline $22 \mathrm{~A} 2$ & $\begin{array}{l}835 / 839(99 \%) \\
\mathrm{E}=0.0\end{array}$ & Pte 3758 & $\begin{array}{l}\text { Plu0658 } \\
\text { Pau00608 }\end{array}$ & 1301 & $\begin{array}{l}\text { Membrane Fusion Protein } \\
\text { PrtC }\end{array}$ \\
\hline $41 \mathrm{~B} 3$ & $\begin{array}{l}934 / 936(99 \%) \\
E=0.0\end{array}$ & Pte 4458 & $\begin{array}{l}\text { Plu } 4762 \\
\text { Pau } 04250\end{array}$ & 259 & $\begin{array}{l}\text { ATP-dependent protease } \\
\text { HslV }\end{array}$ \\
\hline $51 \mathrm{~F} 9$ & $\begin{array}{l}773 / 773(100 \%) \\
\mathrm{E}=0.0\end{array}$ & Pte 2343 & Plu3152 & 291 & $\begin{array}{l}\text { Conserved hypothetical } \\
\text { protein }\end{array}$ \\
\hline $71 \mathrm{H} 4$ & $\begin{array}{l}420 / 420(100 \%) \\
E=0.0\end{array}$ & Pte4077 & $\begin{array}{l}\text { Plu } 4545 \\
\text { Pau04046 }\end{array}$ & 395 & $\begin{array}{l}\text { Similarities with repressor } \\
\text { protein CI }\end{array}$ \\
\hline $90 \mathrm{E} 2$ & $\begin{array}{l}943 / 944(99 \%) \\
\mathrm{E}=0.0\end{array}$ & Pte3758 & $\begin{array}{l}\text { Plu0658 } \\
\text { Pau00608 }\end{array}$ & 191 & $\begin{array}{l}\text { Membrane Fusion Protein } \\
\text { PrtC }\end{array}$ \\
\hline \multicolumn{6}{|c|}{$\begin{array}{l}\text { Defective hemolysis/ } \\
\text { Delayed virulence }\end{array}$} \\
\hline $10 \mathrm{~A} \mathrm{C} 11$ & $\begin{array}{l}942 / 943(99 \%) \\
\mathrm{E}=0.0\end{array}$ & Pte626 & $\begin{array}{l}\text { Plu2384 } \\
\text { Pau02113 }\end{array}$ & 1279 & Exoribonuclease II \\
\hline 10A H12 & $\begin{array}{l}919 / 928(99 \%) \\
E=0.0\end{array}$ & Pte626 & $\begin{array}{l}\text { Plu } 2384 \\
\text { Pau } 02113\end{array}$ & 1279 & Exoribonuclease II \\
\hline $46 \mathrm{G} 6$ & $\begin{array}{l}911 / 919(99 \%) \\
\mathrm{E}=0.0\end{array}$ & Pte4664 & $\begin{array}{l}\text { Plu3016 } \\
\text { Pau01660 }\end{array}$ & 155 & Transposase \\
\hline $50 \mathrm{C5}$ & $\begin{array}{l}942 / 944(99 \%) \\
E=0.0\end{array}$ & Pte2343 & Plu3152 & 291 & $\begin{array}{l}\text { Conserved hypothetical } \\
\text { protein }\end{array}$ \\
\hline $53 \mathrm{H} 3$ & $\begin{array}{l}518 / 518(100 \%) \\
\mathrm{E}=0.0\end{array}$ & Pte 4736 & $\begin{array}{l}\text { Plu } 4849 \\
\text { Pau04355 }\end{array}$ & 285 & $\begin{array}{l}\text { Lipopolysaccharide } \\
\text { heptosyltransferase I }\end{array}$ \\
\hline $79 \mathrm{~B} 5$ & $\begin{array}{l}945 / 945(100 \%) \\
E=0.0\end{array}$ & Pte3808 & $\begin{array}{l}\text { Plu0620 } \\
\text { Pau } 00579\end{array}$ & 147 & $\begin{array}{l}\text { Adenosine (5')- } \\
\left.\text { pentaphospho-( } 5^{\prime \prime}\right)- \\
\text { adenosine } \\
\text { pyrophosphohydrolase }\end{array}$ \\
\hline
\end{tabular}


Table 8 (cont.)

\begin{tabular}{|c|c|c|c|c|c|}
\hline Mutant & $\begin{array}{l}\text { Identity } \\
(\%) \text { E value }\end{array}$ & Gene & $\begin{array}{l}\text { Plu or Pau } \\
\text { homologue }\end{array}$ & Insert Site & $\begin{array}{l}\text { Predicted/Postulated } \\
\text { Gene function }\end{array}$ \\
\hline \multicolumn{6}{|l|}{$\begin{array}{l}\text { Delayed hemolysis/ } \\
\text { WT virulence }\end{array}$} \\
\hline $32 \mathrm{E} 4$ & $\begin{array}{l}570 / 570(100 \%) \\
\mathrm{E}=0.0\end{array}$ & Pte3828 & $\begin{array}{l}\text { Plu0604 } \\
\text { Pau00562 }\end{array}$ & 2638 & $\begin{array}{l}\text { Carbamoyl-phosphate } \\
\text { synthase large chain }\end{array}$ \\
\hline $41 \mathrm{D} 5$ & $\begin{array}{l}777 / 778(99 \%) \\
E=0.0\end{array}$ & Pte3828 & $\begin{array}{l}\text { Plu0604 } \\
\text { Pau00562 }\end{array}$ & 756 & $\begin{array}{l}\text { Carbamoyl-phosphate } \\
\text { synthase large chain }\end{array}$ \\
\hline \multicolumn{6}{|l|}{$\begin{array}{l}\text { Delayed hemolysis/ } \\
\text { Delayed virulence }\end{array}$} \\
\hline $30 \mathrm{C} 6$ & $\begin{array}{l}935 / 935(100 \%) \\
E=0.0\end{array}$ & Pte3828 & $\begin{array}{l}\text { Plu0604 } \\
\text { Pau00562 }\end{array}$ & 746 & $\begin{array}{l}\text { Carbamoyl-phosphate } \\
\text { synthase large chain }\end{array}$ \\
\hline $30 \mathrm{~F} 2$ & $\begin{array}{l}677 / 677(100 \%) \\
E=0.0\end{array}$ & Pte4759 & & 1153 & $\begin{array}{l}\text { Hypothetical protein } \\
\text { (*adjacent to UDP- } \\
\text { glucose 4-epimerase) }\end{array}$ \\
\hline \multicolumn{6}{|l|}{$\begin{array}{l}\text { Early hemolysis/ } \\
\text { WT virulence }\end{array}$} \\
\hline$\overline{86 \mathrm{C} 7}$ & $\begin{array}{l}932 / 934(99 \%) \\
E=0.0\end{array}$ & Pte 1241 & $\begin{array}{l}\text { Plu1619 } \\
\text { Pau02831 }\end{array}$ & & $\begin{array}{l}\text { Phosphoserine } \\
\text { aminotransferase }\end{array}$ \\
\hline
\end{tabular}

Identity (\%) E value: Determines percentage of sequenced nucleotides with exact matches in the genome for the identified gene. Gene: pte number identifies sequence location in P. temperata genome. Plu or Pau homologue: plu and pau numbers identify location of matching gene in $P$. luminescens and $P$. asymbiotica genomes, respectively. Insert Site: Identifies the location of transposon insertion within the gene. Gene function: Putative product produced by the identified gene, based on sequence similarities with other closely related genomes. 


\section{CONFIRMATION OF TRANSPOSON INSERTION SITES BY PCR}

To confirm the location of the transposon insertion identified by rescue cloning, two PCR approaches were used. Initially, primers (Table 2) were used to amplify the genes of interest from genomic DNA. Product sizes were compared to products amplified from the primary parental wild type genomic DNA. The presence of the transposon within a particular gene results in a product size approximately $2.5 \mathrm{~kb}$ larger than the expected product size. This size discrepancy allowed us to determine which gene housed the transposon in one particular mutant of interest, $79 \mathrm{~B}$, where sequencing had indicated a possible overlap of two genes by the transposon.

Sequencing of the rescued plasmid from 79 B5 identified a transposon insertion site 147 bases into pte3808, a gene encoding a nudix protein involved in RNA degradation. Immediately adjacent to this gene is pte3807, a nitrogen regulationassociated phosphocarrier protein kinase/phosphorylase. The expected product size for amplification of pte3808 from genomic DNA with the RT-PCR primers (Table 2) is 370 bp, as observed in the $1^{\circ}$ WT sample (Figure 10a); however, amplification of pte3808 from mutant $79 \mathrm{~B} 5$ yielded a product greater than $3.0 \mathrm{~kb}$, confirming the presence of the transposon within this gene. The expected product size of amplified pte3807 is approximately $0.7 \mathrm{~kb}$, which was observed in both the $1^{\circ} \mathrm{WT}$ and $79 \mathrm{~B} 5$ samples, indicating that the transposon does not overlap pte3807.

In addition to amplifying the genes from genomic DNA to verify transposon location, RT-PCR was used to determine any potential downstream effects of insertion for mutants of interest. End-point RT-PCR can determine whether a gene is expressed and transcript is made, or whether the insertion of the transposon has impeded gene 
expression. Mutant 79 B5 was analyzed for transcription of both pte3808, the location of transposon insertion, and pte3807, the adjacent downstream gene. For both the $1^{\circ}$ and $2^{\circ}$ parental wild types, ample transcript of both pte3808 and pte3807 was present (Figure 10b). 79 B5 lacked transcript for pte3808, indicating that transposon insertion had knocked out all expression of this gene. 79 B5 did, however, retain expression of pte3807, demonstrating that the interruption in pte3808 did not have an effect on the expression of downstream genes. This confirmation indicates that pte3808 is not located within an operon, and that $79 \mathrm{~B} 5$ is a candidate for genetic complementation.

End point RT-PCR was also performed on $46 \mathrm{G} 6$, the mutant with the transposase adjacent to the Hcp locus. Since Hcp is putatively involved in hemolysin activity, we wanted to see if the transposon insertion had downstream effects on this gene, causing the observed phenotypes. RT-PCR on Hcp with HCP Set 5 primers (Table 2) showed that transcript was actually being made for this gene (Data not shown). This result indicates that the transposon insertion in pte4664, the transposase, did not have downstream effects on Hcp expression. 
gDNA

a)

ต



b)



Figure 10. Confirmation of transposon insertion sites via PCR. a) PCR of genomic DNA yielded products of different sizes, confirming transposon location. A: 2-Log DNA Ladder, B: ${ }^{\circ}$ WT pte3808, C: 79 B5 pte3808, D: $1^{\circ}$ WT pte3807, E: 79 B5 pte3807, F: $1^{\circ}$ WT pte 3808 F with pte3807 R, G: empty, H: 79 B5 pte3808 F with pte3807 R, I: 2-Log DNA Ladder, J: pte3808 no template control, K: pte3807 no template control, L: pte3808 F with pte3807 R no template control. b) End-point RT-PCR confirmed there were no downstream effects of transposon insertion. A: 2-Log DNA Ladder, B: $1^{\circ}$ WT pte3808 transcript, C: $2^{\circ}$ WT pte 3808 transcript, D: 79 B5 pte3808 transcript, E: empty, F: pte3808 transcript no template control, G: empty, H: $1^{\circ}$ WT pte 3807 transcript, I: $2^{\circ}$ pte3807 transcript, J: 79 B5 pte3807 transcript, K: empty, L: pte3807 transcript no template control. 


\section{CHAPTER IV}

\section{DISCUSSION}

\section{IDentification of Mutants Altered in Hemolysis and Pathogenesis}

Previous research conducted on the pathogenesis of Photorhabdus has begun to elucidate the virulence mechanisms employed by this organism. However, despite advancements in our understanding of the physiology of Photorhabdus, little knowledge exists on the precise function and mechanisms of the hemolysins in this system. The goals of this study were to investigate the hemolytic activity of Photorhabdus and to identify the relationship between hemolysis and pathogenesis. To accomplish these goals, a series of screening procedures were employed. Initially, a previously constructed 10,000-transposant library containing primary phase mutant $P$. temperata was screened for altered hemolytic activity using a sheep blood agar plate assay. For this screening procedure, time to initiation of hemolysis was used as the criterion for discerning mutants from the wild type. The screen was conducted this way because the plate assay is a qualitative assessment of hemolysis; increased or decreased levels of activity are not identifiable with this method. For a quantitative analysis of hemolytic activity, a liquid hemolysis assay is necessary. This quantitative assay is significantly more labor intensive than the plate method, rendering the screening of this volume of mutants unfeasible. The liquid assay is more suitable for analyzing a smaller subset of mutants, such as the 10 pathogenesis mutants identified in this study. 
The object of screening the library was to identify mutants that were altered in the synthesis, regulation, or secretion of hemolysins; therefore, identified hemolysis mutants were categorized into one of three groups: Defective, Delayed, and Early. By using these classifications, I expected to find some representative types of mutations. I expected that the defective hemolysis mutants, in which hemolytic activity had been completely lost, would contain disruptions in genes related to hemolysin synthesis. Delayed and early hemolysis mutants would therefore likely represent mutants with disruptions in transport mechanisms and regulators or suppressors of hemolysis activity. In reality, I identified mainly genes involved in regulation and transport, but none directly related to hemolysis.

Although labor-intensive, screening the library in this way offers several distinct advantages over site-directed mutagenesis for the investigation of hemolysis. The $P$. temperata genome contains at least 24 genes putatively involved in hemolysis. Direct knock-outs of these genes may be useful for understanding the role of each specific gene in hemolysis, but would not identify additional regulatory elements indirectly involved in hemolysis expression.

A second advantage of screening the library directly is that it generates a smaller pool of mutants that can be tested for pathogenesis. The in vitro pathogenesis assay used in this study is another labor-intensive process; testing the entire transposant library for mutants altered in pathogenesis is not feasible. Therefore, smaller groups of mutants are characterized for virulence. Previously, 86 identified motility mutants were tested for pathogenesis (Michaels, 2006; Rowedder, 2009), and in this study, 74 hemolysis mutants were tested. Although site-directed mutagenesis of hemolysis genes would also create a mutant pool for testing, screening the entire library identifies a larger group of mutants 
with a broader range of mutations, thus providing more opportunities to identify genes involved in pathogenesis.

The $P$. temperata genome is approximately $5 \mathrm{Mb}$ in length, encoding roughly 5,000 genes. When the transposon library was constructed, it was designed to give $2 \mathrm{x}$ coverage of the genome, hence the 10,000 primary-phase mutants. Theoretically, every gene in the genome should then be represented by two mutants. Given that $P$. temperata has 24 putative hemolysin genes, I expected to find approximately 48 mutants with disruptions in hemolysis genes. I also expected to find a number of pleiotropic mutants with disruptions in global regulators and other indirectly-related genes. However, the insertion of the transposon appears to be biased. This means that the $\operatorname{Tn} 5$ has a tendency to recognize hot spots in the genome, resulting in many mutants having insertions in the same gene. I observed this in my study as well; I identified four groups of mutants with insertions in the same genes. None of the 16 mutants for which I identified the site of transposon insertion had disruptions in hemolysis genes. I believe this is due to bias in choosing which mutants to characterize on the genetic level. Although I did find 34 mutants that were altered only in hemolysis, the mutants altered in both hemolysis and pathogenesis were of primary interest in this study, followed by hemolysis mutants that displayed other pleiotropic effects. Choosing these mutants to characterize probably decreased my chances of identifying genes directly related to hemolysis, as those mutants most likely were only affected in hemolysis expression.

The methods used in this study were designed to provide a broader understanding of the genetics involved in the hemolysis and pathogenesis of Photorhabdus. The genes 
and their pleiotropic effects identified in this study contribute new data to the growing insight into the physiological mechanisms of Photorhabdus.

\section{MUltiple Hemolysins are ACTIVe IN PhotorhabDUS}

Although all of the pathogenesis mutants were either defective or delayed for hemolysis on blood agar plates, I expected that these mutants would retain some hemolytic activity in a liquid assay. Data mining in the RAST and IMG (Integrated Microbial Genomes; http://img.jgi.doe.gov/) databases identifies 24 putative hemolysin genes in the $P$. temperata genome, 25 in the $P$. luminescens genome, and 18 in the $P$. asymbiotica genome. These numbers indicate that Photorhabdus most likely contains a variety of different hemolysins and genes involved in the regulation of hemolysis. Moreover, Xenorhabdus has been shown to contain multiple hemolysins which are independently regulated and active at different stages of stationary phase (Brillard et al., 2001). The findings from the liquid assay showed that the 10 pathogenesis mutants did have some hemolytic activity when in liquid culture. These data support the notion that Photorhabdus encodes multiple types of hemolysin, or has paralogs encoding the same hemolysins. This result was expected given the number of putative genes involved in hemolysin expression. This is also consistent with a study by Brillard et al. (2002), which showed evidence of at least two hemolysins in Photorhabdus, and demonstrated that PhlA activity was only detected using a liquid assay. It is likely that some hemolysins may require close cellular contact with the blood cells in order to induce lysis. This may explain why hemolysis was not visible on blood agar, but was detected in liquid culture where the bacterial cells are able to constantly mix with the blood cells. 
Another interesting finding from this assay was that the secondary wild type had hemolytic activity that was equal to, if not slightly higher than, the primary wild type. This finding further supports the idea that different hemolysins are active via different mechanisms. Furthermore, the hemolysins producing annular ring formation on the plate assay are not the same as those active in liquid culture. This notion is consistent with previous findings of hemolytic activity in the secondary phase (Brillard et al., 2002).

\section{HEMOLYTIC ACTIVITY IN PHOTORHABDUS IS CELL-ASSOCIATED}

In 2001, Brillard et al. showed that active hemolysin was secreted from Xenorhabdus into the extracellular medium, and that the culture supernatant retained hemolytic activity. In contrast, Photorhabdus culture was not shown to have a secreted hemolytic compound (Brillard et al., 2001; Brillard et al., 2002). To test this study, I performed a liquid hemolysis assay using three sample types for each culture. My findings confirm the findings of Brillard et al.; bacterial cells must be present in the sample for hemolysis to occur. Furthermore, the highest hemolytic activity is achieved when cells and culture medium are used together. What this may indicate is that the hemolysins secreted by Photorhabdus probably become inactive fairly quickly. The hemolysins in the filter-sterilized supernatant must completely degrade before the assay is complete. In contrast, the PBS-washed cells continue to secrete hemolysin during the assay, but the overall concentration is less than in the original culture medium containing bacterial cells. Additionally, the presence of a cell-associated co-factor may be required for the activity of secreted hemolysins. This may explain why the cells plus culture sample appears to have a synergistic hemolytic effect compared to the cell-only sample. 


\section{HEMOLYSIS MAY NOT BE REQUIRED FOR FULL VIRULENCE}

My initial hypothesis was that the hemolytic activity observed in Photorhabdus assisted the bacteria during insect infectivity. Several studies on Xenorhabdus indicate a possible role of hemolysins in immunoevasion (Brillard et al., 2001; Cowles and Goodrich-Blair, 2005). However, the data from this study imply this may not be the case for Photorhabdus. Most of the hemolysis mutants were not altered in virulence; in fact, only 10 of the 74 hemolysis mutants were confirmed to have delayed pathogenesis. This finding indicates that hemolysis does not play a significant role in pathogenesis. The few mutants that were altered in both hemolysis and pathogenesis are most likely the result of disruptions in global regulatory elements, rather than a correlation between hemolytic activity and virulence. This notion is supported by the genes that were identified for several mutants, described in the following sections.

\section{REGULATION OF HEMOLYSIS AND VIRULENCE IN PHOTORHABDUS}

As previously stated, the majority of the genes identified in this study were regulatory or transport-related. The lipopolysaccharide heptosyltransferase I protein, identified in defective hemolysis/delayed virulence mutant $53 \mathrm{H} 3$, is responsible for attaching the first heptose molecule to Kdo during LPS inner-core synthesis (Grizot et al., 2006). Interestingly, the absence of this heptose is known to cause attenuated virulence in Gram negative bacteria. This coincides with my finding of delayed pathogenesis for this mutant. Incomplete formation of LPS likely also inhibits the adequate secretion of hemolysin, thus resulting in the defective hemolysis of this mutant. Another translocating protein, phosphoserine aminotransferase (PSAT), was identified in early hemolysis mutant $86 \mathrm{C7}$. PSAT catalyzes the second step of the phosphorylated serine biosynthesis 
pathway (Mishra et al., 2010). This enzyme has also been shown to be involved in alanine synthesis (Kim et al., 2010). 86 C7 is affected in almost every phenotype, including a decrease in growth rate, which is not surprising given the likely auxotrophy of this mutant. The disruption in the synthesis of these amino acids likely affects many other intermediates and pathways involved in homeostasis.

The delayed hemolysis/delayed pathogenesis mutant $30 \mathrm{~F} 2$ identified a transposon insertion site within a gene encoding a hypothetical protein of unknown function. However, this gene is immediately upstream of the gene encoding UDP-glucose 4epimerase, the enzyme that catalyzes the stereochemical conversion of UDP-glucose to UDP-galactose (Mori et al., 2008). Many virulence factors are synthesized using UDPgalactose, therefore it would makes sense that this mutant has a delay in pathogenesis if the transposon is affecting transcription of this downstream gene. This is a likely explanation, but QRT-PCR would be needed to determine to what extent the transposon is affecting this gene, if at all.

The defective hemolysis mutant $41 \mathrm{~B} 3$ had a disruption in the ATP-dependent protease HslV. HslV is a heat shock protein that functions as the proteolytic subunit of the two-component ATP-dependent protease HsIVU (Lee et al., 2009). This complex is important in regulatory protein turnover; in this way, inactivation of HslV is probably inhibiting the turnover of hemolysin repressor proteins. Without the inhibition of these repressors, hemolysin activity would continue to be suppressed.

The last two unique mutants, $46 \mathrm{G} 6$ and $71 \mathrm{H} 4$, had transposon insertions in genes that cannot be clearly related to the observed phenotypes. 46 G6 identified a transposase sequence; this transposase actually has seven identical paralogs in the $P$. temperata 
genome. Sequencing from the opposite end of the transposon was able to determine which paralog actually contained the insertion. This transposase is located next to the secreted protein Hcp (hemolysin coregulated protein), which is part of the Type VI secretion system. However, end point RT-PCR determined that this Hcp gene was still producing transcript, which discredits the possibility that the observed phenotypes were due to disruptions with Hcp expression. The disruption in $71 \mathrm{H} 4$ is equally puzzling; this gene has similarities with the lambda phage repressor protein CI, which is involved in the switch between the lysogenic and lytic growth phases (Galkin et al., 2009). This repressor self-cleaves under the SOS response. The most likely explanation is that the proteins coded by these two genes act as regulators to biological intermediates of other pathways that are indirectly related to the expression of hemolysis and virulence.

\section{MEMbrane Fusion Protein PRTC is INVOLVEd in Hemolysis}

Two defective hemolysis mutants, $22 \mathrm{~A} 2$ and $90 \mathrm{E} 2$, had insertions within the same gene, $p r t C$. The insertion sites for these mutants are located $1110 \mathrm{bp}$ apart; therefore, these mutants are not siblings but rather arose independently from one another. Phenotypically, these mutants are indistinguishable; both express primary wild type characteristics with the exception of protease secretion, for which they are defective. This observation is not surprising given that $\operatorname{prt} C$ belongs to the $\operatorname{prt} B C D$ protease $\mathrm{ABC}$ transporter locus (Bowen et al., 2003). PrtC is a membrane-fusion protein (MFP) and is involved in the secretion of the RTX-like metalloprotease PrtA. Although once suspected to be a major virulence factor in Photorhabdus, PrtA actually is involved in the bioconversion of host tissues during late infection. For this reason it is not surprising that $22 \mathrm{~A} 2$ and 90 E2 retained wild type virulence while losing protease activity. 
Interestingly, NCBI's BLAST program identified sequence similarities with a gene encoding HlyD in Serratia odorifera. HlyD is a type I secretion membrane fusion protein involved in the extracellular transport of hemolysin (Pimenta et al., 2005). In E. coli, this

protein spans the periplasm and is responsible for the direct extracellular transport of Hemolysin A (HlyA). Members of the MFP family share structural domain similarities and transport a variety of compounds out of the cell. This suggests the possibility that the PrtC protein of Photorhabdus may share involvement in the transport of hemolysin. Disruption of $\operatorname{prtC}$ may have caused an absence of expression or a structural misfolding of the protein, which would inhibit the exportation of protease and possibly hemolysin as well.

\section{DISCREPANCIES IN Pleiotropic EFFECTS Of IDENTICAL MUTANTS 50 C5 AND 51 F9}

Sequencing of two defective hemolysis mutants, $50 \mathrm{C} 5$ and 51 F9, identified transposon insertion sites at the same positions within pte2343, a gene encoding a conserved hypothetical protein. Phenotypic characterization revealed that these two mutants are physiologically identical, exhibiting primary phase wild type characteristics; however, $50 \mathrm{C} 5$ is a confirmed pathogenesis mutant, while 51 F9 is not. Initial virulence screening of $51 \mathrm{~F} 9$ identified an $\mathrm{LT}_{50}$ and $\mathrm{LT}_{100}$ of $>57 \mathrm{~h}$ and $>65 \mathrm{~h}$, respectively. Both times were delayed by $10 \mathrm{~h}$ when compared to the primary parental wild type. However, the MOI assay did not confirm this delay in pathogenesis at the four cell dosages tested. Genetically, these two mutants are identical; therefore, all phenotypes should be identical as well. There are a few possible explanations as to why only one of these mutants consistently exhibits delayed pathogenesis. 
One such explanation for this discrepancy in virulence may be attributable to the complexity of using a live multicellular organism. Although the in vitro killing assay using Galleria mellonella is an effective means of testing virulence levels (Waterfield et al., 2009), it can also be quite variable due to a number of factors. Some of the difficulties associated with using a live multicellular model are the extreme sensitivity of the larvae to hot and cold temperatures. Also, larval age, feed, conditions during shipment, as well as the overall health of a particular batch of larvae upon arrival all contribute to variability in the testing process. The use of controls helps to ameliorate some of these fluctuations, but inconsistencies between data sets are still possible. The MOI assay for 50 C5 may have been tested on a slightly stronger batch of larvae, resulting in a more noticeable delay in pathogenesis compared to $51 \mathrm{~F} 9$. Testing these two mutants within the same batch of larvae may resolve this discrepancy.

Another possible explanation for the discrepancy could be that 51 F9 may have a double insertion. Southern analysis was only performed on $50 \mathrm{C} 5$, which showed that this mutant contains only one transposon insertion. 51 F9 has not been analyzed by Southern blot, so a possibility remains that this mutant may have multiple transposon insertions. This option could explain the pathogenic incongruity between these two seemingly identical mutants. Southern analysis would need to be performed to rule out this possibility.

\section{Regulatory EfFects of The CaRbaMoyl-Phosphate SYNTHaSe LaRGe Chain}

A second group of hemolysis mutants had transposon insertion sites within the same gene. $30 \mathrm{C} 6,32 \mathrm{E} 4$, and $41 \mathrm{D} 5$ were all delayed for hemolysis and had disruptions in $\operatorname{car} B$, the gene encoding the large subunit of the carbamoyl-phosphate synthetase (CPS) 
holoenzyme. CPS is a heterodimer involved in pyrimidine biosynthesis (Lund et al., 2010). The large subunit specifically catalyzes carbamoyl phosphate formation, while the small subunit hydrolyzes glutamine. Carbamoyl phosphate subsequently functions in arginine and pyrimidine nucleotide synthesis (Holden et al., 1999).

$30 \mathrm{C} 6,32 \mathrm{E} 4$, and 41 D5 display primary wild type characteristics with the exception of siderophore production. These three mutants were unable to grow on CAS agar. This is not surprising given that CAS is a minimal-nutrient medium. Interference with pyrimidine synthesis could easily hinder the production of arginine or other organic compounds required for growth. The resulting auxotrophy would explain why these mutants do not grow on CAS.

Although a definitive role of CPS in hemolysin expression is not immediately clear, it is likely that this disruption causes an incomplete product formation that is in some way involved in the regulation of hemolysis. For instance, irregular protein folding or the absence of a crucial regulatory intermediate could explain the delay in hemolysis initiation. If a particular repressor for hemolysis was malformed in its inducer binding site, then the repressor would continue to interfere with hemolysin expression. Another possibility could be the absence of an activator required to initiate hemolysin expression. Both of these scenarios would cause a lack of hemolysis until the activity of additional hemolysins, under other forms of regulatory control, were able to compensate for the inactive hemolysin. This could explain why hemolysis is not observed until at least $48 \mathrm{~h}$ growth.

One other peculiar observation surrounds these CPS mutants, and that is that 30 C6 is also delayed for pathogenesis, while 32 E4 and 41 D5 are not. 32 E4 and 41 D5 
were both putative pathogenesis mutants during initial screening, but were not confirmed at the four dosages injected during the MOI assays. As explained before with 50 C5 and $51 \mathrm{F9}$, it is possible that variability in insect health during testing biased the confirmation of only $30 \mathrm{C} 6$ as delayed pathogenesis. However, unlike $50 \mathrm{C} 5$ and $51 \mathrm{~F} 9$, these three mutants all have different insertion sites. The insertion site of $30 \mathrm{C} 6$ is the closest to the beginning of the gene; therefore, it is possible that $32 \mathrm{E} 4$ and 41 D5 have enough sequence transcribed to translate into a partially functional protein, whereas the gene function in $30 \mathrm{C} 6$ could be entirely knocked out.

\section{A C11 AND 10A H12 ARE IDENTICAL EXORIBONUCLEASE II MUTANTS}

Molecular analysis of the pathogenesis mutants $10 \mathrm{~A} \mathrm{C11}$ and 10A H12 revealed mutations in the $r n b$ gene which encodes Exoribonuclease II (RNase II). These two mutants are identical; the transposon insertion site within the disrupted gene is the same in both mutants. This finding indicates that these two mutants arose from a single transformed cell; therefore, 10A C11 and 10A H12 are indistinguishable, both genetically and phenotypically. Interestingly, the RNase II gene found in this mutant pair was also found previously in a pathogenesis mutant, UNH1307 (Rowedder, 2009). Similar to UNH1307, 10A C11 and 10A H12 are completely defective for motility, hemolysis, and dye binding on MacConkey and EMB. 10A C11 and 10A H12 are also negative for lipase, although UNH1307 was not tested. These three mutants are not identical, however. UNH1307 is completely defective for protease, antimicrobial activity, and calcofluor binding. 10A C11 and 10A H12 bind calcofluor, and are positive, albeit significantly reduced $(\leq 1 \mathrm{~mm})$, for protease and antimicrobial activity. Although the 
precise insertion site of UNH1307 is unknown, it can be speculated that this mutant is not an identical clone of the other two.

RNase II is a 3' to 5' exoribonuclease and is a key player in RNA maturation and turnover, as well as mRNA decay (Zuo et al., 2006; Domingues et al., 2009). The structure of RNase II is comprised of two cold shock domains, one catalytic domain, and one substrate-binding domain (Zuo et al., 2006; Arraiano et al., 2010). This complex hydrolyzes single-stranded RNA by excising mononucleotides from the 3 ' end, leaving a short oligonucleotide. Enzyme expression and activity is controlled at both the transcriptional and post-transcriptional levels (Domingues et al., 2009) and is also dependent on environmental conditions. For this reason, RNase II may be involved in the stress response of pathogens during infection.

\section{B5 IS AN RNA PYROPHOSPHOHYDROLASE (RPPH) MUTANT}

Molecular analysis of 79 B5, a defective hemolysis/delayed pathogenesis mutant, identified a disruption in $n u d \mathrm{H}$, a gene encoding adenosine (5')-pentaphospho-(5")adenosine pyrophosphohydrolase. This protein is actually an RNA pyrophosphohydrolase $(\mathrm{RppH})$, which is a member of the Nudix hydrolase superfamily. Proteins belonging to the Nudix family have a wide range of functions but are all characterized by their ability to hydrolyze substrates containing a nucleoside diphosphate attached to a functional group, $\underline{X}$ (McLennan, 2006). The general purpose of these proteins is cellular housecleaning and homeostasis by degrading extraneous metabolites and biochemical intermediates. RppH is one particular Nudix protein involved in the initiation of mRNA degradation. RppH cleaves the 5' end of triphosphorylated mRNA to generate a monophosphorylated RNA which in turn is more susceptible to the endonucleolytic 
activity of RNase $\mathrm{E}$ (Deana et al., 2008). In this way, RppH is thought to be involved in initiating the rapid turnover of transcript in prokaryotes.

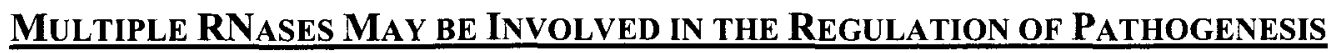

Genetic analysis of mutants altered in pathogenesis identified two different RNases in Photorhabdus: RNase II and RppH. Although the RNase II mutants (10A C11, 10A H12, and UNH1307) and the RppH mutant (79 B5) are not phenotypically identical to one another, it is likely that the cause of the absence of hemolysis and delay in pathogenesis are the same.

RNase II degrades mRNA by hydrolyzing nucleotides from the 3' end of ssRNA. RppH cleaves phosphates from the 5' end of triphosphorylated mRNA, thus marking the message for subsequent degradation by RNase E. Although these mechanisms are slightly different, the end result is the same: mRNA decay. It is likely that, in both cases, the mRNA being degraded encodes repressors of global regulators that ultimately control the expression of hemolysis and virulence factors. If the activity of either RNase II or RppH is knocked out, then the message from which these repressors are translated will not be degraded. This would result in overexpression of the repressors; the global regulators would continue to be suppressed. This suppression could inhibit the production of hemolysins and critical virulence factors, in addition to any other genes under the control of that regulator.

Traditionally, RNA was believed to function only as transcript or to carry out translation. We are just now beginning to fully understand the importance of RNases and non-coding RNAs in the genetic regulation of prokaryotes. Transcriptional activation and repression can be controlled by non-coding RNA, especially under conditions of stress 
(Boots and Moll, 2009). Recent studies also show a definite role of RNases in pathogenesis. Non-coding RNAs have also been shown to regulate the RNA chaperone Hfq, which is involved in virulence (Boots and Moll, 2009). Erova et al. (2008) showed that the exoribonuclease RNase $\mathrm{R}$ is a cold shock protein involved in the pathogenesis of Aeromonas hydrophila. Complementation confirmed that RNase $\mathrm{R}$ is encoded by the virulence-associated gene $v a c B$. Complementation of UNH1307 also showed a restoration of wild type virulence (Rowedder, 2009). To verify the role of RNase II and $\mathrm{RppH}$ in causing the observed hemolysis and pathogenesis phenotypes in my mutants, complementation will need to be performed.

\section{SIGNIFICANCE}

During this study I screened the 10,000-transposant library for hemolysis and identified 74 displaying defective, delayed, or early hemolysis. Subsequent pathogenesis testing confirmed that 10 of these mutants are also delayed for pathogenesis. This finding does not provide evidence for the direct involvement of hemolysins in insect infectivity by Photorhabdus; however, these mutants do provide novel insight into the genes involved in the regulation of both hemolysis and virulence. Genetic characterization of 16 mutants identified a diverse array of regulatory and transport proteins that are involved in the control of hemolysis, and in some cases virulence, in Photorhabdus. One of the most important findings from this study is the further support for the regulatory role of RNases and non-coding RNAs in Photorhabdus. 


\section{FUTURE DiRECTIONS}

The primary focus of this study was to investigate the potential relationship between hemolysis and virulence. This aim was achieved mainly by looking at mutants defective in both characteristics, which excluded the 11 identified early hemolysis mutants. These mutants, however, display some unique characteristics that are worth looking into. Interestingly, although the 11 early hemolysis mutants initiate hemolysis before the primary, these mutants do not appear to have an increased level of hemolytic activity. Although the plate assay method is not quantitative, the early mutants all had zones of hemolysis that were several $\mathrm{mm}$ smaller than the primary parental wild type, despite showing early signs of hemolysis. A liquid assay is necessary to confirm the potential decreased level of hemolysis. This group of mutants could be a very interesting collection to study for mechanisms of transport and regulation, as there appears to be an inverse relationship between the time of hemolysis initiation and the overall level of blood lysing activity. Additionally, a more in depth look at the virulence of these mutants may reveal interesting data. Preliminary screening of hemolysis mutants for pathogenesis defects was primarily focused on the identification of mutants with decreased virulence. Initial screening of the early hemolysis mutants did not identify mutants with enhanced virulence, but a closer look at this group may reveal mutants with enhanced pathogenesis that were previously missed given the focus of this study. An in-depth characterization of this group of mutants would be an interesting and advisable project for an undergraduate. 


\section{LIST OF REFERENCES}

\section{Ahantarig, A., N. Chantawat, N. R. Waterfield, R. ffrench-Constant, and P.}

Kittayapong. 2009. PirAB toxin from Photorhabdus asymbiotica as a larvicide against Dengue vectors. Appl and Environ Microbiol. 75(13):4627-4629.

Akhurst, R. J. 1980. Morphological and functional dimorphism in Xenorhabdus spp., bacteria symbiotically associated with the insect pathogenic nematodes Neoaplectana and Heterorhabditis. Microbiology. 121:303-309.

Arraiano, C. M, R. G. Matos, and A. Barbas. 2010. RNase II The finer details of the Modus operandi of a molecular killer. RNA Biol. 7(3):276-281.

Aziz, R. K., D. Bartels, A. A. Best, M. DeJongh, T. Disz, R. A. Edwards, K. Formsma, S. Gerdes, E. M. Glass, M. Kubal, F. Meyer, G. J. Olsen, R. Olson, A. L. Osterman, R. A. Overbeek, L. K. McNeil, D. Paarmann, T. Paczian, B. Parrello, G. D. Pusch, C. Reich, R. Stevens, O. Vassieva, V. Vonstein, A. Wilke, and O. Zagnitko. 2008. The RAST Server: rapid annotations using subsystems technology. BMC Genomics. 9:75.

Beecher, D. J., and A. C. L. Wong. 1994. Improved purification and characterization of hemolysin BL, a hemolytic dermonecrotic vascular permeability factor from Bacillus cereus. Infect Immun. 62(3):980-986.

Blackburn, M., E. Golubeva, D. Bowen, and R. H. ffrench-Constant. 1998. A novel insecticidal toxin from Photorhabdus luminescens, Toxin complex a (Tca), and its histopathological effects on the midgut of Manduca sexta. Appl and Environ Microbiol. 64(8):3036-3041.

Blackburn, M. B., J. M. Domek, D. B. Gelman, and J. S. Hu. 2005. The broadly insecticidal Photorhabdus luminescens toxin complex a (Tca): activity against the Colorado potato beetle, Leptinotarsa decemlineata, and sweet potato whitefly, Bemisia tabaci. J Insect Sci. 5:32.

Boemare, N. E., R. J. Akhurst, and R. G Mourant. 1993. DNA relatedness between Xenorhabdus spp. (Enterobacteriaceae), symbiotic bacteria of entomopathogenic nematodes, and a proposal to transfer Xenorhabdus luminescens to a new genus, Photorhabdus gen. nov. Int J Syst Evol Microbiol. 43(2):249-255. 
Boemare, N., C. Laumond, and H. Mauleon. 1996. The entomopathogenic nematodebacterium complex: biology, life cycle and vertebrate safety. Biocontrol Sci Technol. 6:333-345.

Boemare, N., J.-O. Thaler, and A. Lanois. 1997. Simple bacteriological tests for phenotypic characterization of Xenorhabdus and Photorhabdus phase variants. Symbiosis. 22:167-175.

Boots, J. L. and I. Moll. 2009. The impact of non-coding RNAs. EMBO Reports. 10:563-567.

Bowen, D. J., T. A. Rocheleau, C. K. Grutzmacher, L. Meslet, M. Valens, D. Marble, A. Dowling, R. ffrench-Constant, and M. A. Blight. 2003. Genetic and biochemical characterization of PrtA, and RTX-like metalloprotease from Photorhabdus. Microbiology. 148:1581-1591.

Brillard, J., E. Duchaud, N. Boemare, F. Kunst, and A. Givaudan. 2002. The PhlA hemolysin from the entomopathogenic bacterium Photorhabdus luminescens belongs to the two-partner secretion family of hemolysins. J Bacteriol. 184(14):3871-3878.

Brillard, J., C. Ribeiro, N. Boemare, M. Brehélin, and A. Givaudan. 2001. Two distinct hemolytic activities in Xenorhabdus nematophila are active against immunocompetent insect cells. Appl Environ Microbiol. 67(6):2515-2525.

Burnell, A. M., and S. P. Stock. 2000. Heterorhabditis, Steinernema and their bacterial symbionts - lethal pathogens of insects. Nematology. 2(1):31-42.

Chattopadhyay, A., N. B. Bhatnagar, and R. Bhatnagar. 2004. Bacterial insecticidal toxins. Crit Rev Microbiol. 30(1):33-54.

Ciche, T. A., S. B. Bintrim, A. R. Horswill, and J. C. Ensign. 2001. A phosphopantetheinyl transferase homolog is essential for Photorhabdus luminescens to support growth and reproduction of the entomopathogenic nematode Heterorhabditis bacteriophora. J Bacteriol. 183(10):3117-3126.

Ciche, T. A., and J. C. Ensign. 2003. For the insect pathogen Photorhabdus luminescens, which end of a nematode is out? Appl and Environ Microbiol. 69(4):1890-1897. 
Clarke, D. J., and B. C. A. Dowds. 1995. Virulence mechanisms of Photorhabdus spp. Strain K122 toward wax moth larvae. J Invertebr Pathol. 66:149-155.

Cowles, K. N. and H. Goodrich-Blair. 2005. Expression and activity of a Xenorhabdus nematophila haemolysin required for full virulence towards Manduca sexta insects. Cell Microbiol. 7(2):209-219.

Deana, A., H. Celesnik, and J. G. Belasco. 2008. The bacterial enzyme RppH triggers messenger RNA degradation by 5' pyrophosphate removal. Nature. 451:355-358.

Domingues, S., R. G. Matos, F. P. Reis, A. M. Fialho, A. Barbas, and C. M Arraiano. 2009. Biochemical characterization of the RNase II family of exoribonucleases from the human pathogens Salmonella typhimurium and Streptococcus pneumoniae. Biochemistry. 48:11848-11857.

Dowling, A. J., N. R. Waterfield, M. C. Hares, G. Le Goff, C. H. Streull, and R. H. ffrench-Constant. 2007. The Mcf1 toxin induces apoptosis via the mitochondrial pathway and apoptosis is attenuated by mutation of the BH3-like domain. Cell Microbiol. 9(10):2470-2484.

Duchaud, E., C. Rusniok, L. Frangeul, C. Buchrieser, A. Givaudan, S. Taourit, S. Bocs, C. Boursaux-Eude, M. Chandler, J. F. Charles, E. Dassa, R. Derose, S. Derzelle, G. Freyssinet, S. Gaudriault, C. Médigue, A. Lanois, K. Powell, P. Siguier, R. Vincent, V. Wingate, M. Zouine, P. Glaser, N. Boemare, A. Danchin, and F. Kunst. 2003. The genome sequence of the entomopathogenic bacterium Photorhabdus luminescens. Nat Biotechnol. 21(11):1307-1313.

Eleftherianos, I., S. Joyce, R. H. ffrench-Constant, D. J. Clarke, and S. R. Reynolds. 2010. Probing the tri-trophic interaction between insects, nematodes and Photorhabdus. Parasitology. 137:1695-1706.

Erova, T. E., V. G. Kosykh, A. A. Fadl, J. Sha, A. J. Horneman, and A. K. Chopra. 2008. Cold shock Exoribonuclease $\mathrm{R}$ (VacB) is involved in Aeromonas hydrophila pathogenesis. J Bacteriol. 190(10):3467-3474.

Farmer, J. J. III, J. H. Jorgensen, P. A. D. Grimont, R. J. Akhurst, G. O. Poinar, Jr., E. Ageron, G. V. Pierce, J. A. Smith, G. P. Carter, K. L. Wilson, and F. W. Hickman-Brenner. 1989. Xenorhabdus luminescens (DNA hybridization Group 5) from human clinical specimens. J Clin Microbiol. 27(7):1594-1600. 
Fischer-Le Saux, M., V. Viallard, B. Brunel, P. Normand, and N. E. Boemare. 1999.

Polyphasic classification of the genus Photorhabdus and proposal of new taxa: $P$. luminescens subsp. luminescens subsp. nov., P. luminescens subsp. akhurstii subsp. nov., $P$. luminescens subsp. laumondii subsp. nov., $P$. temperata sp. nov., $P$. temperata subsp. temperata subsp. nov. and $P$. asymbiotica $\mathrm{sp}$. nov. Int J Syst Bacteriol. 49:1645-1656.

ffrench-Constant, R. H., N. Waterfield, V. Burland, N. T. Perna, P. J. Daborn, D. Bowen, and F. R. Blattner. 2000. A genomic sample sequence of the entomopathogenic bacterium Photorhabdus luminescens W14: potential implications for virulence. Appl and Environ Microbiol. 66(8):3310-3329.

ffrench-Constant, R. H., A. Dowling, and N. R. Waterfield. 2007. Insecticidal toxins from Photorhabdus bacteria and their potential use in agriculture. Toxicon. 49:436-451.

Galkin, V. E., X. Yu, J. Bielnicki, D. Ndjonka, C. E. Bell, and E. H. Egelman. 2009. Cleavage of bacteriophage $\lambda$ cI repressor involved the RecA C-terminal domain. $J$ Mol Biol. 385:779-787.

Georgis, R. 1990. Formulation and application technology, p.173-191. In R. Gaugler and H. K. Kaya (eds.), Entomopathogenic nematodes in biological control. CRC Press, Boca Raton, FL.

Georgis, R., A. M. Koppenhöfer, L. A. Lacey, G. Bélair, L. W. Duncan, P. S.

Grewal, M. Samish, L. Tan, P. Torr, and R. W. H. M. van Tol. 2006. Successes and failures in the use of parasitic nematodes for pest control. Biol Control. 38:103-123.

Gerrard, J. G., N. R. Waterfield, and M. Sanchez-Contreeras. 2011. Photorhabdus asymbiotica: shedding light on a human pathogenic bioluminescent bacterium. Clinical Microbiology Newsletter. 33(14):103-109.

Givaudan, A. and A. Lanois. 2000. flhDC, the flagellar master operon of Xenorhabdus nematophilus: requirement for motility, lipolysis, extracellular hemolysis, and full virulence in insects. J Bacteriol. 182(1):107-115.

Goodrich-Blair, H. and D. J. Clarke. 2007. Mutualism and pathogenesis in Xenorhabdus and Photorhabdus: two roads to the same destination. Mol Microbiol. 64(2):260-268. 
Grizot, S., M. Salem, V. Vongsouthi, L. Durand, F. Moreau, H. Dohi, S. Vincent, S. Escaich, and A. Ducruix. 2006. Structure of the Escherichia coli heptosyltransferase WaaC: binary complexes with ADP AND ADP-2-deoxy-2fluoro heptose. J Mol Biol. 363:383-394.

Hertle, R. 2005. The family of Serratia type pore forming toxins. Curr Protein Pept Sci. 6(4):313-325.

Hertle, R., M. Hilger, S. Weingardt-Kocher, and I. Walev. 1999. Cytotoxic action of Serratia marcescens hemolysin on human epithelial cells. Infect Immun. 67(2):817-825.

Hodgson, M. M., B. Day, D. J. White, and L. S. Tisa. 2003. Effect of growth conditions on the motility of Photorhabdus temperata. Arch Microbiol. 180:1724.

Holden, H. M., J. B. Thoden, and F. M. Raushel. 1999. Carbamoyl phosphate synthetase: an amazing biochemical odyssey from substrate to product. Cell Mol Life Sci. 56:507-522.

Kim, S. H., B. L. Schneider, and L. Reitzer. 2010. Genetics and regulation of the major enzymes of alanine synthesis in Escherichia coli. J Bacteriol. 192(20):5304-5311.

Lanois, A., S. Pages, S. Bourot, A.-S. Canoy, A. Givaudan, and S. Gaudriault. 2011. Transcriptional analysis of a Photorhabdus sp. variant reveals transcriptional control of phenotypic variation and multifactorial pathogenicity in insects. Appl Environ Microbiol. 77(3):1009-1020.

Lee, J. W., E. Park, M. S. Jeong, Y. J. Jeon, S. H. Eom, J. H. Seol, and C. H. Chung. 2009. HslVU ATP-dependent protease utilizes maximally six among twelve threonine active sites during proteolysis. J Biol Chem. 284(48):33475-33484.

Lund, L., Y. Fan, Q. Shao, Y. Q. Gao, and F. M. Raushel. 2010. Carbamate transport in carbamoyl phosphate synthetase: a theoretical and experimental investigation. $\mathrm{J}$ Am Chem Soc. 132:3870-3878.

McLennan, A. G. 2006. The Nudix hydrolase superfamily. Cell Mol Life Sci. 63:123-143. 
Michaels, B. 2006. Ph.D. thesis. University of New Hampshire, Durham, NH. Genetics and physiology of motility by Photorhabdus spp.

Michaels, B. and L. S. Tisa. 2011. Swarming motility by Photorhabdus temperata is influenced by environmental conditions and uses the same flagella as that used in swimming motility. Can J Microbiol. 57(3):196-203.

Mishra, V., V. Ali, T. Nozaki, and V. Bhakuni. 2010. Entamoeba histolytica phosphoserine aminotransferase (EhPSAT): insights into the structure-function relationship. BMC Research Notes. 3:52.

Mori, T., H. Suenaga, and K. Miyazaki. 2008. A metagenomic approach to the identification of UDP-glucose 4-epimerase as a menadione resistance protein. Biosci Biotechnol Biochem. 72(6):1611-1614.

Murray, M. G. and W. F. Thompson. 1980. Rapid isolation of high molecular weight plant DNA. Nucleic Acids Res. 8(19):4321-4325.

Ondraczek, R., S. Hobbie, and V. Braun. 1992. In vitro activation of the Serratia marcescens hemolysin through modification and complementation. J Bacteriol. 174(15):5086-5094.

Pimenta, A. L., K. Racher, L. Jamieson, M. A. Blight, and I. B. Holland. 2005. Mutations in HlyD, part of the type I translocator for hemolysin secretion, affect the folding of the secreted toxin. J Bacteriol. 187(21):7471-7480.

Pimentel, D. 1997. Pest management in agriculture, p. 1-11. In D. Pimentel (ed.), Techniques for reducing pesticide use: environmental and economic benefits. John Wiley \& Sons, Chichester, UK.

Pimentel, D. and A. Greiner. 1997. Environmental and socio-economic costs of pesticide use, p. 51-78. In D. Pimentel (ed.), Techniques for reducing pesticide use: environmental and economic benefits. John Wiley $\&$ Sons, Chichester, UK.

Rodou, A., D. O. Ankrah, and C. Stathopoulos. 2010. Toxins and secretion systems of Photorhabdus luminescens. Toxins. 2:1250-1264.

Rowedder, H. 2009. Master's thesis. University of New Hampshire, Durham, NH. Identification of Photorhabdus temperata motility mutants altered in insect pathogenesis. 
Schwyn, B. and J. B. Neilands. 1987. Universal chemical assay for the detection and determination of siderophores. Anal Biochem. 160:47-56.

Waterfield, N. R., T. Ciche, and D. Clarke. 2009. Photorhabdus and a host of hosts. Annu Rev Microbiol. 63:557-574.

Weisburg, W. G., S. M. Barns, D. A. Pelletier, and D. J. Lane. 1991. 16S ribosomal DNA amplification for phylogenetic study. J Bacteriol. 173(2):697-703.

Wilkinson, P., N. R. Waterfield, L. Crossman, C. Corton, M. Sanchez-Contreras, I. Vlisidou, A. Barron, A. Bignell, L. Clark, D. Ormond, M. Mayho, N. Bason, F. Smith, M. Simmonds, C. Churcher, D. Harris, N. R. Thompson, M. Quail, J. Parkhill, and R. H. ffrench-Constant. 2009. Comparative genomics of the emerging human pathogen Photorhabdus asymbiotica with the insect pathogen Photorhabdus luminescens. BMC Genomics. 10:302.

Yang, G., A. J. Dowling, U. Gerike, R. H. ffrench-Constant, and N. R. Waterfield. 2006. Photorhabdus virulence cassettes confer injectable insecticidal activity against the wax moth. J Bacteriol. 188(6):2254-2261.

Zuo, Y., H. A. Vincent, J. Zhang, Y. Wang, M. P. Deutscher, and A. Malhotra. 2006. Structural basis for processivity and single-strand specificity of RNase II. Mol Cell. 24:149-156. 